U.S. Department of Transportation

Federal Highway Administration
Publication No. FHWA-RD-95166

December 1995

\title{
The Effects of Age, Spatial A bility, and Navigational Information on Navigational Performance
}

Research and Development Turner-Fairbank Highway Research Center 6300 Georgetown Pike McLean, Virginia 22101-2296 


\section{FOREWORD}

This report presents the results of a laboratory study that examined the relationship between age, spatial ability, and navigational skill. The results were that older drivers and drivers with lower spatial ability showed worse navigational performance than younger drivers and drivers with higher spatial ability. However, a simulated in-vehicle turn-by-turn route guidance display enhanced navigational performance for both older and younger drivers, and for drivers with varying spatial abilities. The study was conducted in the VIDSIM laboratory, a part-task driving simulator that is part of the Human Factors Laboratory at the Federal Highway Administration's (FHWA ) Turner-Fairbank Highway Research Center in McLean, Virginia.

Sufficient copies of the report are being distributed to provide a minimum of two copies to each FHWA regional and division office, and five copies to each State highway agency. Direct distribution is being made to division offices.

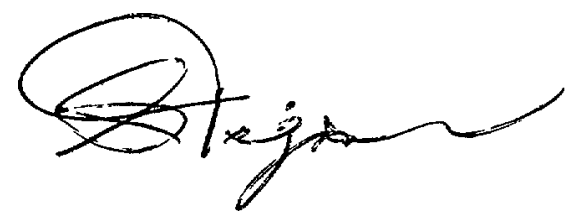

Samuel C. Tignor, Ph.D., Acting Director

Office of Safety and Traffic Operations

Research and Development

\section{NOTICE}

This document is disseminated under the sponsorship of the Department of Transportation in the interest of information exchange. The United States Government assumes no liability for its contents or use thereof. This report does not constitute a standard, specification, or regulation.

The United States Government does not endorse products or manufacturers. Trade and manufacturers' names appear in this report only because they are considered essential to the object of the document. 
Technical Report Documentation Page

\begin{tabular}{|c|c|}
\hline $\begin{array}{l}\text { 1. Report No. } \\
\qquad \text { FHWA-RD-95-166 }\end{array}$ & 3. Recipient's Catalog No. \\
\hline 4. Title and Subtitle & 5. Report Date $\quad$ December 1995 \\
\hline INFORMATION ON NAVIGATIONAL PERFORMANCE & 6. Performing Organization Code \\
\hline $\begin{array}{l}\text { 7. Author(s) } \\
\text { K. Wochlnger and D. Boehm-Davis }\end{array}$ & 8. Performing Organization Report No. \\
\hline 9. Performing Organization Name and Address & $\begin{array}{r}\text { 10. Work Unit No. (TRAIS) } \\
\text { 3A6b-0082 }\end{array}$ \\
\hline 1710 Goodridge Drive, MS 1-6-6 & $\begin{array}{l}\text { 11. Contract or Grant No. } \\
\text { DTFH61 }-94-C-00003\end{array}$ \\
\hline McLean, Virginia 22102 & 13. Type of Report and Period Covered \\
\hline $\begin{array}{l}\text { 12. Sponsoring Agency Name and Address } \\
\text { Office of Safety and Traffic Operations Research \& Development }\end{array}$ & $\begin{array}{l}\text { Final Report } \\
\text { January - August } 1994\end{array}$ \\
\hline $\begin{array}{l}\text { Federal Highway Administration } \\
6300 \text { Georgetown Pike, McLean, Virginia 22101-2296 }\end{array}$ & 14. Sponsoring Agency Code \\
\hline
\end{tabular}

15. Supplementary Notes

Contracting Officer's Technical Representative (COTR): Dr. Truman M. Mast (HSR-30)

FHWA Human Factors Laboratory Manager: Ms. Elizabeth Alicandri (HSR-30)

\section{Abstract}

The purpose of the study reported here was to examine whether age and spatial ability are factors that influence a driver's ability to navigate and to use navigational displays. These factors were examined because previous research suggests that spatial ability may underlie navigational performance, including route-following and mapreading, and that these skills may diminish with age. Thus, older drivers and drivers with weak navigational skills, may have a heightened need for, and be particularly served by, in-vehicle route guidance displays found in Advanced Traveler Information Systems (ATIS).

A total of 56 drivers were tested on spatial ability. The drivers then performed a navigational task in a part-task driving simulator using different navigational aids, including: (1) text directions, (2) an enlarged, mounted paper map, (3) a standard-scale paper map, and (4) a turn-by-turn route guidance ATIS display. The major findings were that: (1) older drivers showed worse navigational performance than younger drivers, (2) the worse performance found in the older group was attributable to their lower spatial ability, (3) spatial ability predicted navigational performance, and (4) a simulated ATIS turn-by-turn display enhanced navigational performance. The implications of the results are that navigational ability declines with age due to decrements in spatial ability and perceptual speed, and ATIS route guidance has the potential to facilitate navigational performance in drivers of varying spatial abilities and age.

\section{Key Words}

Older drivers, spatial ability, ATIS, navigational information, navigational displays, route-following

\section{Distribution Statement}

No restrictions. This document is available to the public through the National Technical Information Service (NTIS), Springfield, Virginia 22161
19. Security Classif. (of this report)

Unclassified

Form DOT F 1700.7 (8-72)

(PF V2.1, 12/1 3/93)
20. Security Classif. (of this page)

Unclassified

21. No. of Pages

53

22. Price

Reproduction of completed page authorized 


\section{METRIC/ENGLISH CONVERSION FACTORS}

\section{ENGLISH TO METRIC}

LENGTH (APPROXI MATE)

1 inch $(\mathrm{in})=2.5$ centimeters $(\mathrm{cm})$

1 foot $(\mathrm{ft})=30$ centimeters $(\mathrm{cm})$

1 yard (yd 0.9 meter $(\mathrm{m})$

$1 \mathrm{mile}(\mathrm{mi})=1.6 \mathrm{ki}$ lometers $(\mathrm{km})$

AREA (APPROXI MATE)

1 square inch ( $\mathrm{sq}$ in, $\mathrm{in}^{2}=6,5$ square centimeters $\left(\mathrm{cm}^{2}\right)$

1 square foot (sq $f t, f^{2}=0.09$ square meter $\left(\mathrm{m}^{2}\right)$

1 square yard $\left(s q y d, y d^{2}\right)=0.8$ square meter $\left(m^{2}\right)$

1 square mile $\left(\mathrm{sq} \mathrm{mi}, \mathrm{mi}^{2}\right)=2.6$ square kilometers $\left(\mathrm{km}^{2}\right)$

1 acre $=0,4$ hectares $($ he $)=4,000$ square meters $\left(\mathrm{m}^{2}\right)$

MASS - WEIGHT (APPROXIMATE)

1 ounce $(0 z)=28$ grams $(g r)$

1 pound $(\mid \mathrm{b})=.45 \mathrm{kilogram}(\mathrm{kg})$

1 short ton $=2,000$ pounds $(L b)=0,9$ tonne $(t)$

VOLUME (APPROXI MATE)

1 teaspoon (tsp) $=5$ milliliters $(\mathrm{ml})$

l tablespoon (tbsp a 15 milliliters ( $\mathrm{ml}$ )

1 fluid ounce $(\mathrm{fl}$ oz $)=30$ milliliters $(\mathrm{ml})$

1 cup $(c)=0.24$ liter (I)

1 pint (pt) $=0.47$ liter (I)

1 quart (qt) $=0.96$ liter (I)

l gallon (gal) $=3.8$ liters (I)

1 cubic foot (cu ft, $\left.\mathrm{ft}^{3}\right)=0.03$ cubic meter $\left(\mathrm{m}^{3}\right)$

1. cubic yard (cu yd, $\left.y d^{3}\right)=0.76$ cubic meter $\left(\mathrm{m}^{3}\right)$

TEMPERATURE (EXACT)

$[(x-32)(5 / 9)]{ }^{0} \mathrm{~F}$ 口 y ${ }^{0} \mathrm{C}$
METRI C TO ENGLISH

LENGTH (APPROXIMATE)

1 millimeter $(\mathrm{mm})=0.04$ inch (in)

1 centimeter $(\mathrm{cm})=0.4$ inch (in)

1 meter $(\mathrm{m})=3.3$ feet $(\mathrm{ft})$

1 meter $(m)=1.1$ yards $(y d)$

1 kilometer $(\mathrm{km})=0.6 \mathrm{mile}(\mathrm{mi})$

AREA (APPROXI MATE)

1 square centimeter $\left(\mathrm{cm}^{2}\right)=0.16$ square inch (sq in, in ${ }^{2}$ )

1 square meter $\left(\mathrm{m}^{2}\right)=1.2$ square yards (sq $\left.y d, \mathrm{yd}^{2}\right)$

1 square kilometer $\left(\mathrm{km}^{2}\right)=0.4$ square $\mathrm{mile}\left(\mathrm{sq} \mathrm{mi}, \mathrm{mi}^{2}\right.$ )

1 hectare $($ he $)=10,000$ square meters $\left(\mathrm{m}^{2}\right)=2.5$ acres

MASS - WEIGHT (APPROXIMATE)

1 gram $(g r)=0.036$ ounce $(02)$

1 kilogram $(k g)=2.2$ pounds $(\mid \mathrm{b})$

1 tonne $(t)=1,000$ kilograms $(\mathrm{kg})=1,1$ short tons

VOLUME (APPROXI MATE)

1 milliliters (ml) 0.03 fluid ounce $(\mathrm{fl}$ 0z)

1 Iiter (1) $=2.1$ pints (pt)

1 Iiter (I) $=1.06$ quarts (qt)

l Iiter (I) $=0.26$ gallon (gal)

1 cubic meter $\left(\mathrm{m}^{3}\right)=36$ cubic feet $\left(\mathrm{cu} \mathrm{ft}, \mathrm{ft}^{3}\right)$

1 cubic meter $\left(\mathrm{m}^{3}\right)=1.3$ cubic yards (cu yd, $\mathrm{yd}^{3}$ )

QUICK INCH.CENTIMETER LENGTH CONVERSION

I NCHES

CENTI METERS

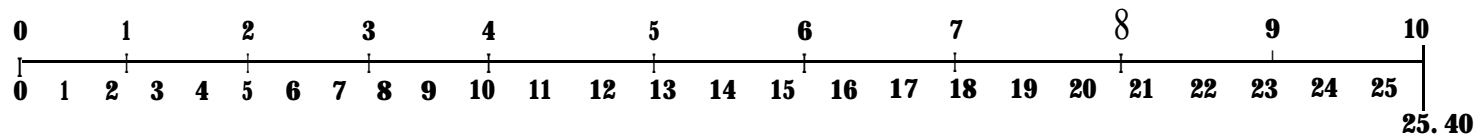

QUI CK FAHRENHEIT. CELSIUS TEMPERATURE CONVERSION

\begin{tabular}{|c|c|c|c|c|c|c|c|c|c|c|c|c|c|c|}
\hline $.40^{\circ}$ & $.22^{\circ}$ & $.4^{\circ}$ & $14^{\circ}$ & $32^{\circ}$ & $50^{\circ}$ & $68^{\circ}$ & $86^{\circ}$ & $104^{\circ}$ & $122^{\circ}$ & $140^{\circ}$ & $158^{\circ}$ & $176^{\circ}$ & $194^{\circ}$ & $212^{\circ}$ \\
\hline $.40^{\circ}$ & $\cdot 30^{\circ}$ & $\cdot 20^{\circ}$ & $=10^{\circ}$ & $0^{\circ}$ & $10^{\circ}$ & $20^{\circ}$ & $30^{\circ}$ & $40^{\circ}$ & 50 & $60^{\circ}$ & $70^{\circ}$ & $80^{\circ}$ & $90^{\circ}$ & 100 \\
\hline
\end{tabular}

For more exact and or other conversion factors, see NBS Miscellaneous Publication 286, Units of Weights and

Measures. Price \$2,50, SD Catalog No, Cl 310286. 


\section{TABLE OF CONTENTS}

$\underline{\text { Section }}$

INTRODUCTION. ..............................

Older Drivers. . . . . . . . . . . . . . . . . . . . 1

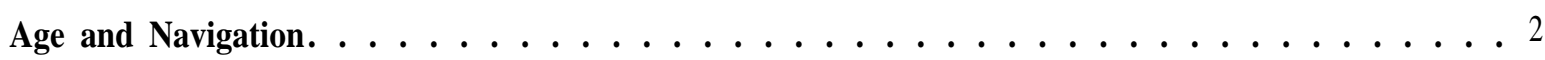

Spatial Ability and Navigation. . . . . . . . . . . . . . . . . . 2

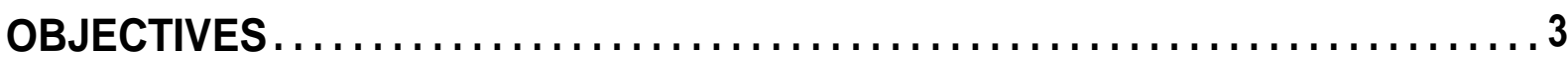

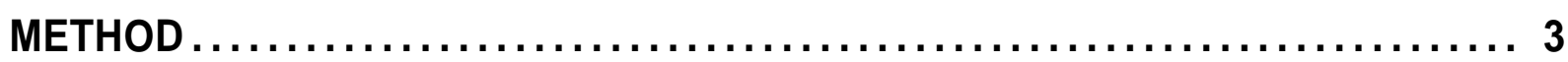

Subjects.............................................................. 3

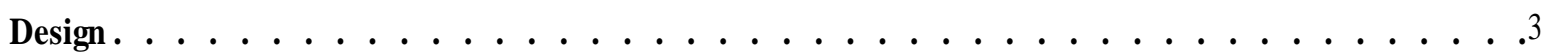

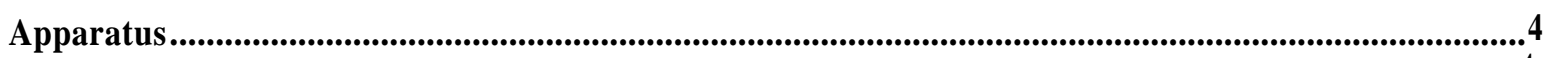

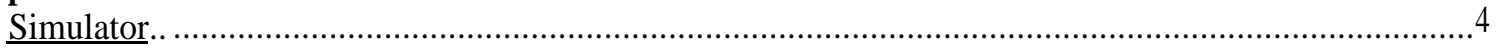

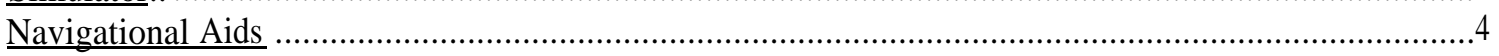

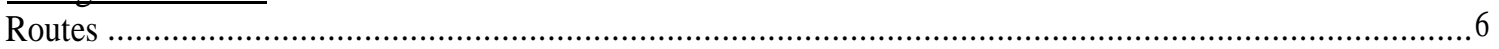

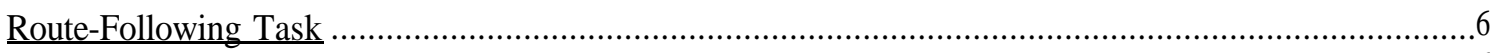

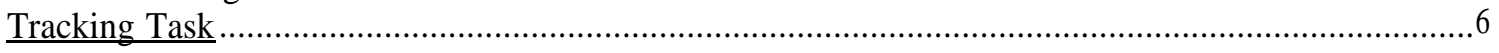

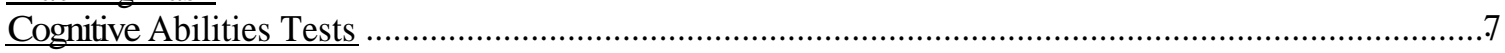

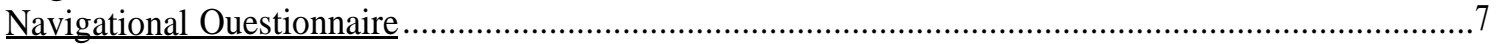

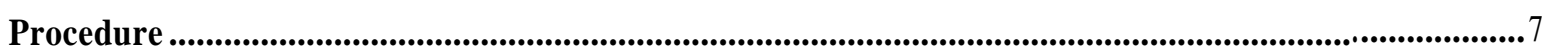



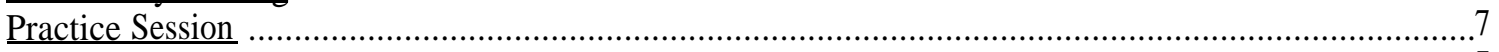

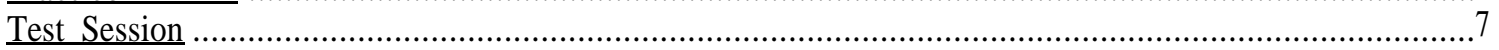

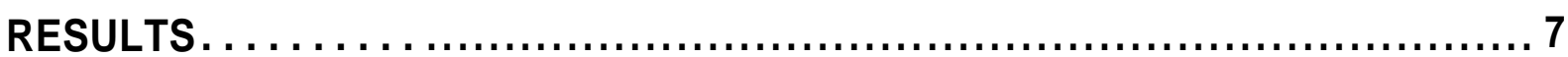

Route-Following Performance ............................................................................................................................7

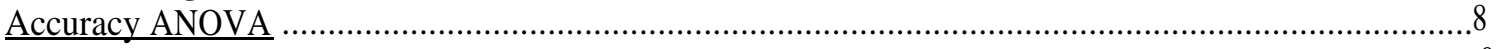

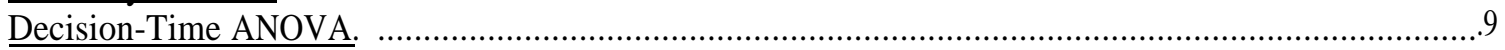

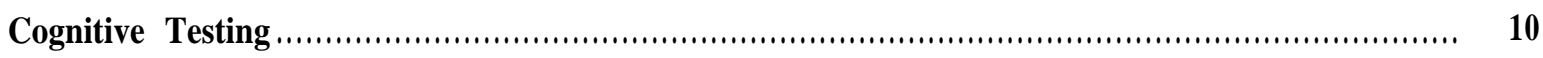

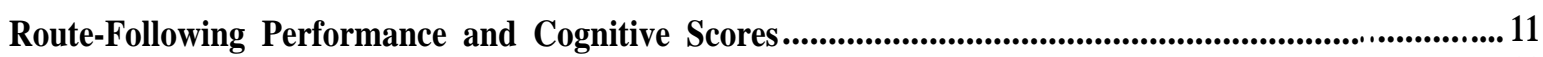

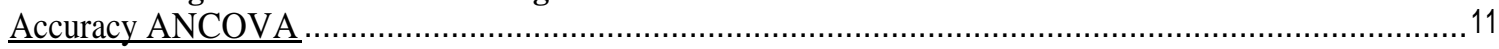

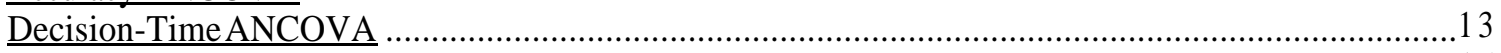

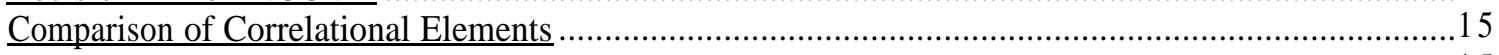

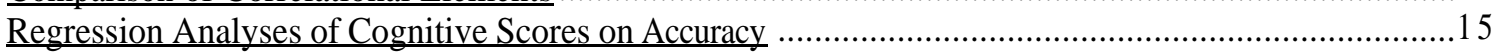

Specific Comparisons: Aae and Performance with ATIS ................................................................ 16 


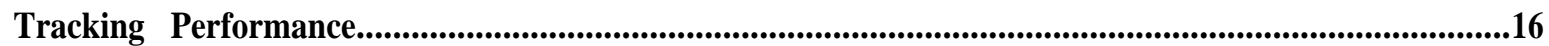

Repeated-Measures



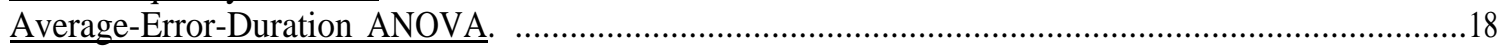

Questionnaire Results ....................................................................................................................................19

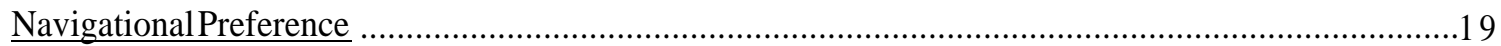

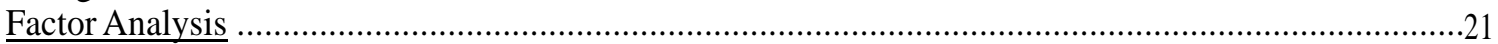



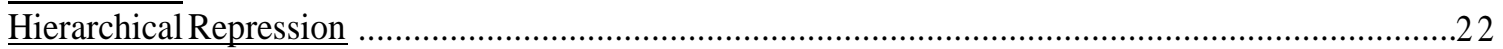

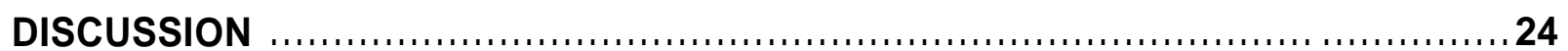

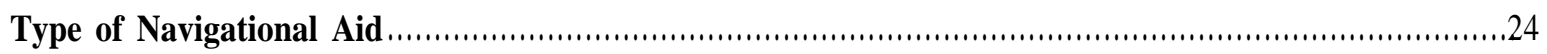



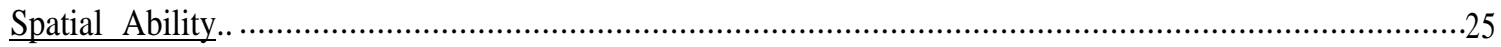

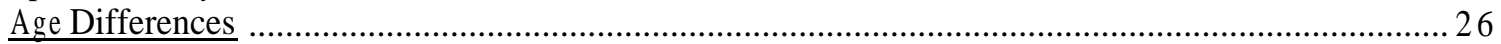

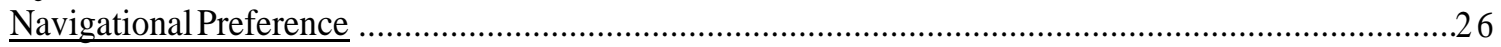

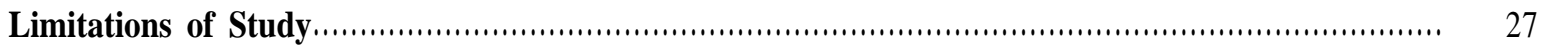

Summary

APPENDIX A. NAVIGATIONAL QUESTIONNAIRE .................................. 29

APPENDIX B. SUBJECT INSTRUCTIONS …..................................... 33

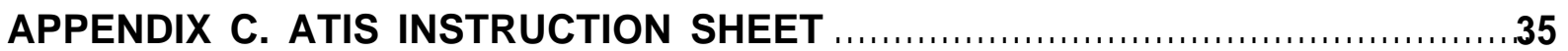

APPENDIX D. ANALYSES OF RESPONSES 1 AND $2 \ldots \ldots \ldots \ldots \ldots \ldots \ldots \ldots$

APPENDIX E. RESULTS OF SIMULTANEOUS MULTIPLE REGRESSION

ANALYSES PREDICTING ACCURACY OR DECISION TIME WITH THE

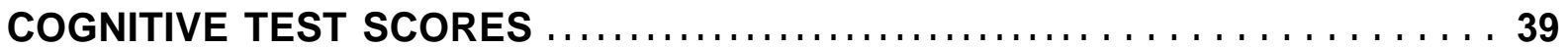

APPENDIX F. PREDICTING ACCURACY AND DECISION TIME WITH THE COGNITIVE TEST SCORES AND FACTOR SCORES $\ldots \ldots \ldots \ldots \ldots \ldots \ldots \ldots \ldots, \ldots \ldots \ldots$

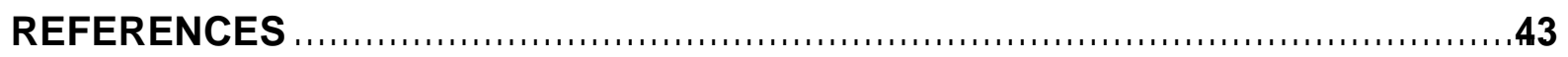




\section{LIST OF FIGURES}

$\underline{\text { Figure }}$

$\underline{\text { Page }}$

1. Diagram of the part-task driving simulator .................................. 4

2. Simulated ATIS turn-by-turn display ....................................... 5

3. Average accuracy by age group and navigational aid .......................... .8

4. Average decision time by age group and navigational aid ....................... 9

5. Average accuracy by spatial ability group and navigational aid ................ 13

6. Average accuracy after removing the influence of spatial ability ............... 14

7. Average decision time after removing the influence of perceptual speed ....... 14

8. Average number of tracking errors by age group and navigational aid ........ 17

9. Average duration of tracking error by age group and navigational aid ......... 18

10. Breakdown of driver preferences for receiving directions .................... 21

11. Breakdown of driver preferences for giving directions ....................... 21

12. Accuracy for responses 1 and 2 by age group and navigational aid ........... 38

13. Decision time for responses 1 and 2 by age group and navigational aid ........ 38 


\section{LIST OF TABLES}

$\underline{\text { Table }} \quad \underline{\text { Page }}$

1. Example of text directions .................................................. 5

2. Newman-Keuls pairwise mean comparisons of accuracy by navigational aid ... .9

3. Newman-Keuls pairwise mean comparisons of decision time by navigational aid ......................................................................... 10

4. Results of cognitive testing by gender and age group ..................... 10

5. Intercorrelation of cognitive test scores ....................................... 11

6. Correlations between accuracy, decision time, and cognitive test scores ....... 12

7. Summary of simultaneous multiple regression results showing the cognitive constructs with significant betas for each navigational aid ...................... 16

8. Newman-Keuls pairwise mean comparisons of tracking-error frequency by navigational aid

9. Newman-Keuls pairwise mean comparisons of average tracking error duration by navigational aid ................................................ 18

10. Preference ratings and standard deviations by gender and age group .......... 19

11. Perceived ability ratings and standard deviations by gender and age group ., . 19

12. Percentage preferring to get directions in words or maps by gender and age

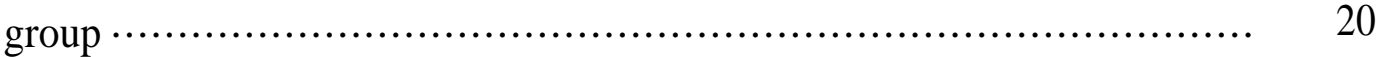

13. Percentage preferring to give directions in words or maps by gender and age group ..................................................................... 20

14. Factor loadings for principal-axis extraction and varimax rotation resulting in a two-factor solution ........................................................ 23

15. Correlational matrix of factor scores, accuracy, and decision time ............ 23

16. Summary of hierarchical regression results for accuracy ..................... 24

17. Accuracy with ATIS ........................................................ 39

18. Accuracy with text directions .............................................. 39

19. Accuracy with the large paper map.......................................... 39

20. Accuracy with the standard paper map ..................................... 39

21. Decision time with ATIS ................................................. 40

22. Decision time with the text directions ........................................ 40

23. Decision time with the large paper map .................................. 40

24. Decision time with the standard paper map .............................. 40

25. Accuracy with text directions ............................................... 41

26. Accuracy with the standard paper map ..................................... 41

27. Accuracy with ATIS ..................................................... 41

28. Accuracy with the large map ............................................. 42 


\section{INTRODUCTION}

Advanced Traveler Information Systems (ATIS) provide in-vehicle travel-related information and navigational assistance to drivers. ATIS uses data obtained from roadway-based sensors, traffic site reports, and traffic management centers to update estimated trip times, provide alternative routes, and display route guidance.(") One goal of ATIS is to improve driver navigation by conveying route guidance via simple, turn-by-turn displays. As much as 6 percent to 9 percent of all travel time is attributable to driver navigational error, costing millions of dollars annually in wasted fuel, traffic delays, and higher risk of accidents. ${ }^{(2-4)}$ It follows that improving driver navigation would result in increased roadway capacity.

The success of ATIS at reducing travel time will be determined, in part, by the extent to which ATIS improves the navigational efficiency of all drivers. In this sense, knowledge about the sources of differences in driver navigational ability could be used in the design and evaluation of route guidance systems. As discussed below, earlier research points to spatial ability as a likely factor influencing navigational ability. Furthermore, age-related decrements in spatial ability suggest that older drivers may have diminished navigational ability relative to younger drivers.

The purpose of the study reported here was to address these questions by measuring the extent that ATIS improved navigational ability for drivers with different levels of navigational skill, including older drivers and drivers with lower spatial ability.

\section{Older Drivers}

The safety and mobility of older drivers, generally defined as 65 years of age and older, are increasingly relevant to transportation research. ${ }^{(5)}$ Due to an increasingly aging population, both the number and proportion of older drivers are rising. It is estimated that by 2020,17 percent (50 million people) of the U.S. population will consist of people age 65 and older, compared to 12 percent in 1988. ${ }^{(6)}$ Also, the proportion of older adults licensed to drive is increasing. For example, 60 percent of older adults (at least age 65) were licensed to drive in 1980, compared to 70 percent in 1989. In contrast, the increase in the total driving population during that period was 2.1 percent $(84.5$ percent and 86.6 percent, respectively),$(7,8)$

Aging is characterized by a global reduction in attention resources, leading to reductions in cognition and perception. ${ }^{(9)}$ Age-related deficits occur in language, memory, spatial ability, and conceptualization. ${ }^{(10-13)}$ Visual ability also deteriorates with age across a wide range of functions, including light sensitivity, acuity, visual field, night vision, color vision, and spatial resolution. . $^{(14-16)}$

Cognitive and visual deficits increase the difficulty of the driving task for older individuals. This difficulty may explain why older drivers are among the most hazardous in the population in terms of crash risk per mile.@) It is perhaps in compensation for these deficits 
that older drivers often choose to drive during daylight, off-peak hours, and on lightly traveled roads. ${ }^{(17)}$ Despite these precautions, older drivers are overrepresented in accidents involving turns, merges, and yielding the right of way. ${ }^{(18)}$ Older drivers are also more likely than other drivers to suffer serious injury or death in crashes. ${ }^{(6)}$

\section{Age and Navigation}

Older adults often suffer a decline in way-finding skills that constrain their mobility even in neighborhoods familiar to them. ${ }^{(19)}$ Older adults are less familiar with the geography of their neighborhoods than younger people, they restrict themselves to smaller areas, and they draw neighborhood maps with less accuracy and organization. ${ }^{(19)}$ Furthermore, age-related reduction in spatial ability may affect map-reading and navigational skills. ${ }^{(13)}$ For example, older individuals develop inefficient and inaccurate route plans, and they recognize fewer landmarks than do younger people. ${ }^{(20,21)}$

Declines in way-finding skills limit the mobility of older drivers due to the increased likelihood (and possibly fear) of getting lost. But alternative means of transportation are notably lacking in most areas, so driving often remains the first choice of transportation mode. However, as described above, driving (as well as reading maps, choosing routes from maps, and following directions) can be difficult tasks for older adults. It follows that route guidance systems, which are designed to simplify navigation, might enhance the performance of all drivers, including older drivers.

A potential problem with route guidance systems is that drivers may not easily divide attention between the display in the vehicle and the external, forward view. The visual and spatial processing required to match the characteristics of the roadway to the display may distract the driver from the primary task of safely handling the vehicle. Older drivers, in particular, may be vulnerable to any distracting effects of in-vehicle displays. Research has shown that older adults have particular difficulty in divided-attention tasks. ${ }^{(22)}$ For these reasons, it is important to evaluate the effects of age on route-following when using route guidance systems.

\section{Spatial Ability and Navigation}

Another factor that may affect performance with route guidance systems is spatial ability. Spatial ability is the component of intelligence that processes information about the relationships among objects. It is distinct from verbal, mathematical, and reasoning abilities and is a relatively stable dimension of intelligence. ${ }^{(11,23-26)}$ Individuals vary widely in their ability to solve both simple and complex spatial problems. ${ }^{(24-28)}$ High-spatial-ability individuals are able to encode spatial information more easily, more accurately, and in more detail than low-spatial-ability individuals. ${ }^{(23)}$

Spatial ability is involved in navigational aspects of the driving task, including routefollowing and map-reading. Route-following requires a range of spatial skills, such as 
recognizing terrain, being aware of one's direction and orientation, and comparing the spatial features of the real-world to their representations on navigational aids.(")

Map-reading requires spatial ability. High-spatial-ability individuals are likely to have good map-reading skil1s. ${ }^{(30-32)}$ In contrast, low-spatial-ability individuals are likely to read maps poorly and make less accurate navigational decisions. Spatial ability is also a factor in related areas, such as navigational preferences, habits, and experiences, as well as sense of direction and spatial orientation. ${ }^{(33,34)}$ Some drivers prefer verbal directions, and perform worse when working with spatially based maps. ${ }^{(33)}$ These drivers may take more time to access and process spatial information. As a result, paper maps may have limited appeal and usefulness to these drivers. Written verbal directions, consisting of linear lists of turns and devoid of spatial information, may be more useful to people with poor spatial skills.

\section{OBJECTIVES}

This research had two related objectives. The first was to evaluate driver navigational performance with an ATIS route guidance display and traditional aids, including paper maps and text directions. The second was to evaluate the effects of driver differences in spatial ability and age on navigational ability. These objectives are related because knowledge about the relationship between age, spatial ability, and navigational performance can be applied to the evaluation of the capacity of ATIS route guidance to improve the navigational performance for drivers with varying navigational skills. To understand the relationship between age, spatial ability, and the ability to follow a route with different types of navigational information, subjects were tested on their spatial ability and they performed a route-following task in a part-task driving simulator. In addition, subjects completed a navigational questionnaire that assessed navigational styles, preferences, and habits.

\section{METHOD}

Subjects

Fifty-six licensed drivers participated in this study. Half the subjects were part of a younger group (30 to 45 years old) and half were part of an older group (65 to 75 years old), each balanced by gender. Subjects met a minimum of 20/40 corrected vision. Subjects were recruited from a subject listing maintained by the Human Factors Laboratory at the Federal Highway Administration's Turner-Fairbank Highway Research Center (TFHRC). Each subject was paid \$20 for participating in the 2-h session.

\section{Design}

The study u s ed a 2 (age group) x 2 (gender) x 4 (type of navigation aid) mixed experimental design. The type of navigational aid was the within-subjects variable. Subjects performed a navigational task under four conditions, using: (1) text directions. (2) 
a paper map that was enlarged 225 percent, (3) a standard-scale paper map, and (4) an ATIS turn-by-turn route guidance display. Subjects also performed a secondary tracking task. Repeated measures of route-following and tracking performance were collected. Route-following performance was measured by navigational accuracy and decision time. Tracking performance was measured by error frequency and error duration.

\section{Apparatus}

Simulator. Each s u bj ect wa s tested in a part-task driving simulator, consisting of a driving buck facing a 914-mm (36-in) Mitsubishi television monitor and a 152-mm (6-in) JVC monitor to the subject's right (see figure 1). A keypad with three arrow keys (left, right, and straight) was placed behind the steering wheel within easy reach of the subject. A personal computer controlled two NEC PC-VCR's that played videotapes of a real-world route on the Mitsubishi monitor and a matching turn-by-turn route guidance display on the JVC monitor. A laser tracking device was controlled separately by a TANDY 1400 computer.

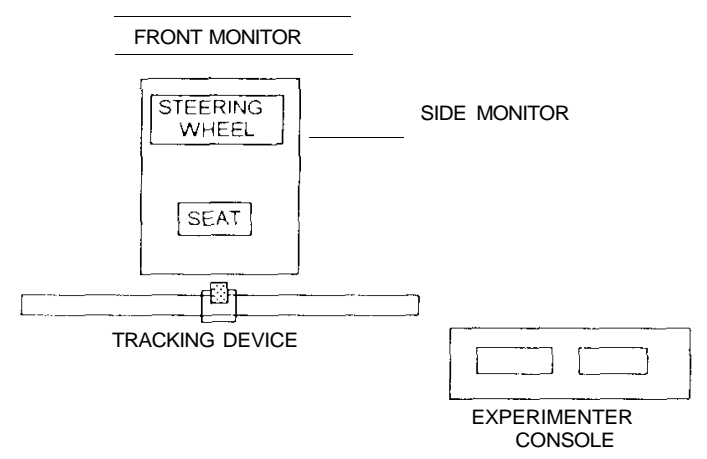

Figure 1. Diagram of the part-task driving simulator.

Navigational Aids. The navigational aids were a paper street map, a large paper map, text directions printed on paper, and an ATIS turn-by-turn display. The route was highlighted on both paper maps. The text directions described the route in terms of the number of blocks and street names. An example of text directions is shown in table 1. (Note that the actual font size used was CG Times Scalable 25 point.) 
Table 1. Example of text directions.

You are heading southeast on Holly Avenue.
Take the second left onto Aspen Avenue N.
Take the second right onto Ash Road W.
Take the second left onto Alder Avenue.
Take the fourth left onto Derby Avenue W.
Take the second right onto York Road.
Take the first right onto Laurel Avenue W.
Take the second right onto Vernon Street N.
Take the first left onto Vernon Court W.
Stop at the end of the street.

Both the large paper map and text directions were clipped to the front of the side monitor, so that these aids had the same distance from the subject as the turn-by-turn display. Each subject was allowed to either hold or place on the dashboard or lap the standard paper map, but it could not be clipped to the side monitor. The ATIS display was a simulation of a route guidance system, displayed on a 152-mm (6-in), color monitor located to the right of the subject. An example of the ATIS display is in figure 2.

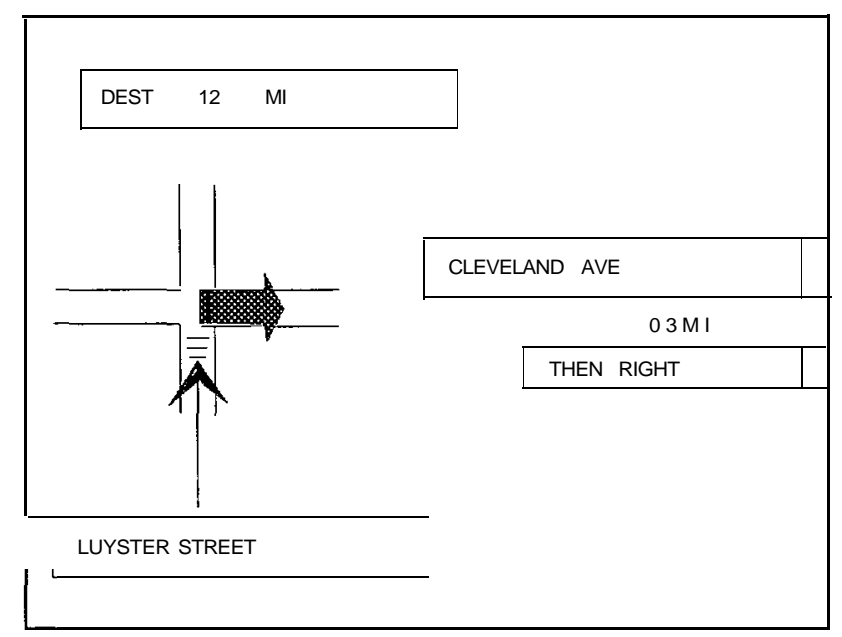

Figure 2. Simulated ATIS turn-by-turn display. 
Router.outes were videotaped in a suburban area with a wide-angle lens at about 33 $\mathrm{km} / \mathrm{h}$ from the driver's perspective. Each route was $5 \mathrm{~min}$ long, taped during the same time of day. Routes were similar in terms of the type and number of turns and traffic density. Each type of navigational aid was created for each route.

Route-Following Task. The goal of the route-following task was to use the navigational aid to follow a real-world route recorded from the driver's perspective. The videotaped route was presented on the forward monitor and was paused occasionally just before an intersection. During the pause, the subject indicated which way the car should go, based on the navigational aid, by pressing the corresponding directional arrow key on the keypad located behind the steering wheel. After the subject responded, street names were superimposed on the monitor. The names were imposed because the real street signs were illegible on the videotape. The subject then made a second response, which could be the same or different than the first response. The tape resumed play immediately following the second response. The videotape followed the proper path, regardless of the subject's response. Both the accuracy of the navigational response and decision time were recorded for each response. The first measure of decision time was based on the time it took for the subject to press one of the arrow keys from the moment the tape paused. The second measure of decision time was based on the time it took for the subject to press a key after the street names were displayed on the screen.

Tracking Task. The goal of the task was to keep a semi-randomly moving laser-generated red oval light within fixed boundaries on the bottom of the front monitor. A warning tone sounded when the light went out of bounds. During the pauses when the subject made a navigational response, the light was paused; the light resumed movement after the subject finished the second response and the videotape resumed play. Performance measures included error frequency (the number of times the light went out of bounds) and error duration (the number of minutes it remained out of bounds).

The purpose of including the tracking task was to provide workload that simulated the control required for driving. The difficulty of the tracking task was determined by the light's rate of travel in degrees per second. The rate used in the current study was 3.22 degrees/s, and was based on the tracking performance of five pilot subjects, ages 65 to 70 years, in a previous study. ${ }^{(36)}$ The pilot subjects were able to keep the light within bounds for at least 80 percent of a 1-min trial at this rate.

Cognitive Abilities Tests. Measures of cognitive ability were collected with tests from the Manual for Kit of Factor-Referenced Cognitive Tcsts. ${ }^{(3)}$ These tests are paper-and-pencil tests that require only a few minutes to complete. Each test provides instructions and a practice section with answers. The Maze Tracing Speed, Card Rotations, and Map Planning tests were used to measure different components of spatial ability. The Maze Tracing Speed test required subjects to trace a path through a maze with a pencil. The Card Rotations test required subjects to identify matching spatial figures. The Map Planning test required subjects to plan the shortest path from one point to another amidst a series of 
blockades. The Hidden Words Test was used to measure verbal ability, and required subjects to identify words in a vector of random letters. The Identical Pictures test measured perceptual speed and required subjects to compare visual figures and symbols in as short a time as possible.

Navigational Ouestionnaire. The questionnaire, shown in appendix A, had newly designed questions as well as questions from previous research about navigational preferences, habits, and experiences. ${ }^{(33)}$ It measured self-reported navigational abilities and preferences. The questionnaire used a five-point rating scale with seven questions on self-appraisal of navigational ability and eight questions on navigational preferences.

\section{Procedure}

Preliminarv Testing. Prior to testing in the part-task driving simulator, each subject signed an informed-consent statement. A Bausch and Lomb Ortho-Rater was used to test and screen each subject for minimum visual acuity. Each subject then completed the cognitive test battery and the navigational questionnaire.

Practice Session. The subject was seated in the driving buck of the part-task simulator and the experimenter read instructions to the subject (shown in appendix B). The subject practiced the tracking task for $2 \mathrm{~min}$. Then the subject practiced the route-following task while tracking, using each type of navigational aid for $3 \mathrm{~min}$. The subject practiced with all four aids before the test session. An ATIS instruction sheet described the display (shown in appendix C). After practice, the subject was given an opportunity to take a break, but not all subjects chose to take one.

Test Session. Assignment of the navigational aid and the routes were randomized. The subject was given up to 3 min to study each navigational aid before the task began. (For the ATIS display, subjects reviewed the ATIS instruction sheet.) The subject performed the route-following task with each navigational aid in conjunction with the tracking task. After the study was completed, the subject was debriefed and paid \$20 for participating.

\section{RESULTS}

\section{Route-Following Performance}

Route-following performance was measured in terms of accuracy and decision time. Navigational accuracy was defined as the average number of incorrect responses made per route. Since there were 11 pauses, during which the subject had to make 2 responses (once before and once after the street names were displayed), there were a total of 22 responses.

Decision time was defined as the average time taken to make a decision for the first and second response. The first and second responses were combined in order to evaluate the 
overall performance for all subjects. (See appendix D for a description of analyses conducted for responses 1 and 2 separately.)

A 2 (age) x 2 (gender) x 4 (navigational aid) repeated-measures multiple analysis of variance (MANOVA) was performed with navigational accuracy and decision time as the dependent variables. The MANOVA showed a significant main effect for age $(\mathrm{F}(2,52)=$ $5.63, \mathrm{p}=0.006)$, and navigational aid $(\mathrm{F}(6,47)=23.26, \mathrm{p}<0.001)$. There was no main effect found for gender $(\mathrm{F}(2,51)=0.53, \mathrm{p}=0.593)$. In addition, there were no statistically significant interactions among the independent variables.

Accuracy ANOVA Following the significant MANOVA, a 2 (age) x 4 (navigational aid) repeated-measures analysis of variance (ANOVA) was performed on navigational accuracy. As expected, significant main effects for age $(F(1,51)=5.53, p=0.023)$ and navigational aid $(\mathrm{F}(3,156)=18.88, \mathrm{p}<0.001)$ were found. The younger group, with an average of 1.80 incorrect responses across all navigational aids, was more accurate than the older group, with an average of 3.04 incorrect responses. The average number of incorrect navigational responses made by each group for each type of navigational aid is shown in figure 3 .

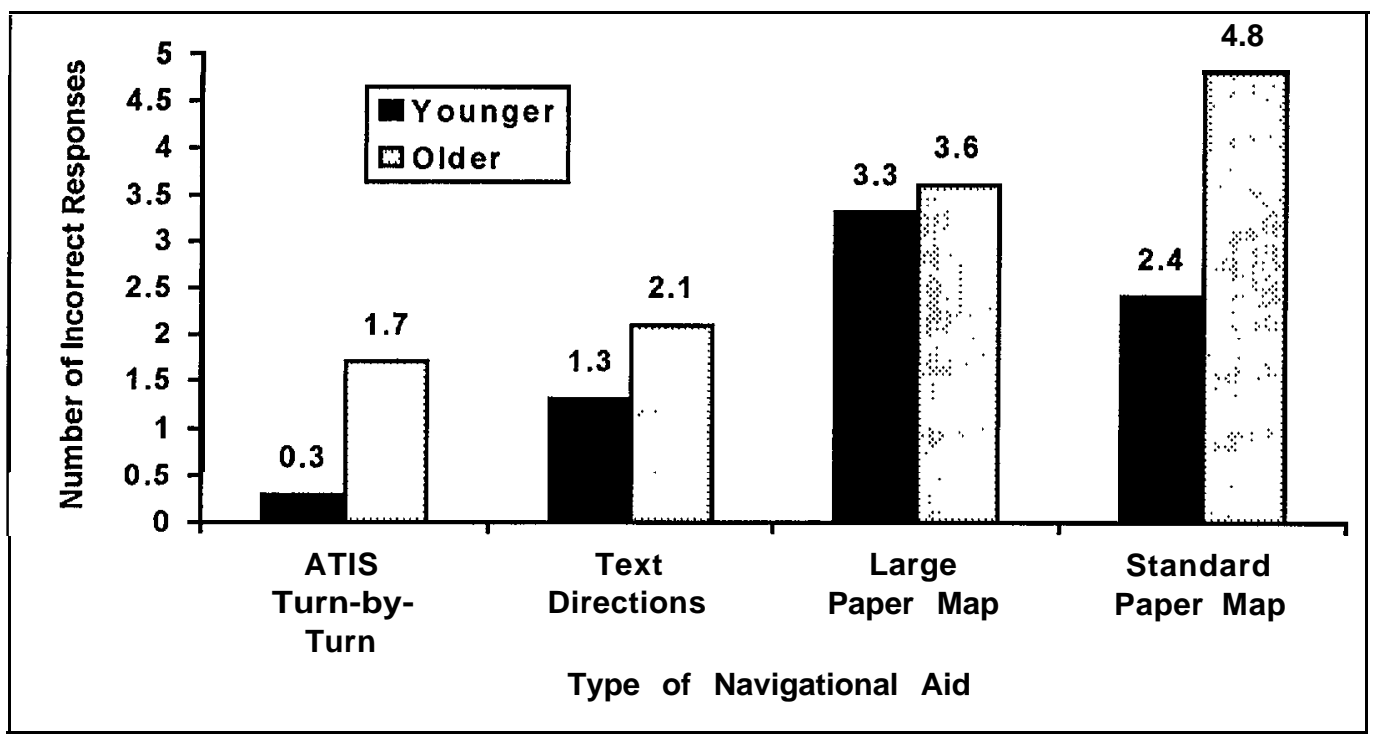

Figure 3. Average accuracy by age group and navigational aid.

Following the ANOVA, Newman-Keuls pairwise comparisons were performed on the accuracy means for each navigational aid, as shown in table 2. Subjects made the fewest navigational errors using ATIS $($ mean $=0.982)$, followed by the text directions (mean= $1.661)$, the large map $($ mean $=3.429)$, and the standard map $($ mean= 3.625). The comparisons were made with a critical value of $1.38(\mathrm{p}<0.01)$ and revealed significant differences between: (1) the large map and the ATIS, (2) the large map and the text 
blockades. The Hidden Words Test was used to measure verbal ability, and required subjects to identify words in a vector of random letters. The Identical Pictures test measured perceptual speed and required subjects to compare visual figures and symbols in as short a time as possible.

Navigational Questionnaire. The questionnaire, shown in appendix A, had newly designed questions as well as questions from previous research about navigational preferences, habits, and experiences. ${ }^{(33)}$ It measured self-reported navigational abilities and preferences. The questionnaire used a five-point rating scale with seven questions on self-appraisal of navigational ability and eight questions on navigational preferences.

\section{Procedure}

Preliminary Testing. Prior to testing in the part-task driving simulator, each subject signed an informed-consent statement. A Bausch and Lomb Ortho-Rater was used to test and screen each subject for minimum visual acuity. Each subject then completed the cognitive test battery and the navigational questionnaire.

Practice Session. The subject was seated in the driving buck of the part-task simulator and the experimenter read instructions to the subject (shown in appendix B). The subject practiced the tracking task for 2 min. Then the subject practiced the route-following task while tracking, using each type of navigational aid for $3 \mathrm{~min}$. The subject practiced with all four aids before the test session. An ATIS instruction sheet described the display (shown in appendix C). After practice, the subject was given an opportunity to take a break, but not all subjects chose to take one.

Test Session. Assignment of the navigational aid and the routes were randomized. The subject was given up to 3 min to study each navigational aid before the task began. (For the ATIS display, subjects reviewed the ATIS instruction sheet.) The subject performed the route-following task with each navigational aid in conjunction with the tracking task. After the study was completed, the subject was debriefed and paid \$20 for participating.

\section{RESULTS}

\section{Route-Following Performance}

Route-following performance was measured in terms of accuracy and decision time. Navigational accuracy was defined as the average number of incorrect responses made per route. Since there were 11 pauses, during which the subject had to make 2 responses (once before and once after the street names were displayed), there were a total of 22 responses.

Decision time was defined as the average time taken to make a decision for the first and second response. The first and second responses were combined in order to evaluate the 
overall performance for all subjects. (See appendix D for a description of analyses conducted for responses 1 and 2 separately.)

A 2 (age) x 2 (gender) x 4 (navigational aid) repeated-measures multiple analysis of variance (MANOVA) was performed with navigational accuracy and decision time as the dependent variables. The MANOVA showed a significant main effect for age $(\mathrm{F}(2,52)=$ $5.63, \mathrm{p}=0.006)$, and navigational aid $(\mathrm{F}(6,47)=23.26, \mathrm{p}<0.001)$. There was no main effect found for gender $(F(2,51)=0.53, p=0.593)$. In addition, there were no statistically significant interactions among the independent variables.

Accuracy ANOVA. Following the significant MANOVA, a 2 (age) x 4 (navigational aid) repeated-measures analysis of variance (ANOVA) was performed on navigational accuracy. As expected, significant main effects for age $(\mathrm{F}(1) 51)=5.53, \mathrm{p}=0.023)$ and navigational aid $(\mathrm{F}(3,156)=18.88, \mathrm{p}<0.001)$ were found. The younger group, with an average of 1.80 incorrect responses across all navigational aids, was more accurate than the older group, with an average of 3.04 incorrect responses. The average number of incorrect navigational responses made by each group for each type of navigational aid is shown in figure 3 .

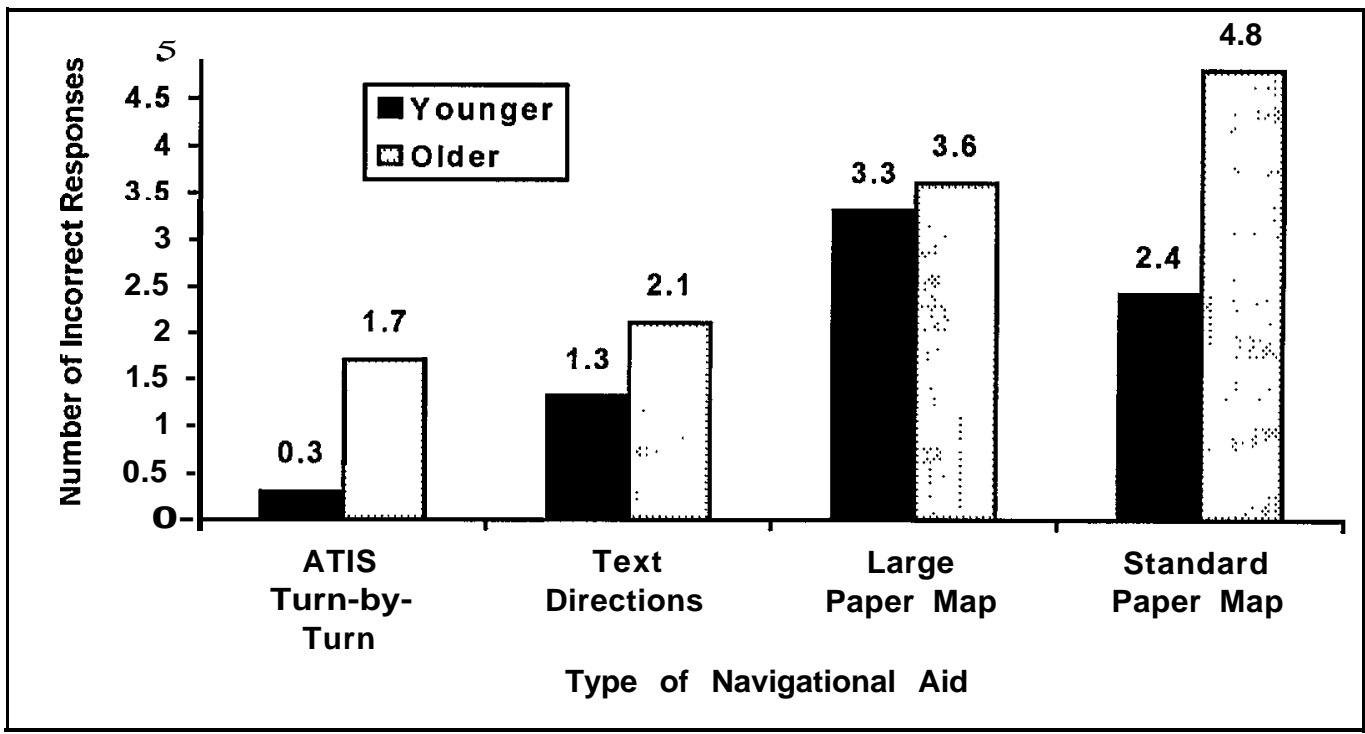

Figure 3. Average accuracy by age group and navigational aid.

Following the ANOVA, Newman-Keuls pairwise comparisons were performed on the accuracy means for each navigational aid, as shown in table 2. Subjects made the fewest navigational errors using ATIS (mean $=0.982$ ), followed by the text directions (mean= $1.661)$, the large map (mean=3.429), and the standard map $($ mean= 3.625). The comparisons were made with a critical value of $1.38(\mathrm{p}<0.01)$ and revealed significant differences between: (1) the large map and the ATIS, (2) the large map and the text 
directions, (3) the standard map and the ATIS, and (4) the standard map and the text directions. There was no statistical difference between the standard map mean and the large map mean, or between the text directions mean and the ATIS mean.

Table 2. Newman-Keuls pairwise mean comparisons of accuracy by navigational aid.

\begin{tabular}{|c|c|c|c|c|}
\cline { 2 - 5 } \multicolumn{1}{c|}{} & $\begin{array}{c}\text { TURN-BY } \\
\text { TURN } \\
\text { Mean = 0.982) }\end{array}$ & $\begin{array}{c}\text { TEXT } \\
\text { (Mean= 1.661) }\end{array}$ & $\begin{array}{c}\text { LARGE MAP } \\
(\text { Mean= 3.429) }\end{array}$ & $\begin{array}{c}\text { SANDARD } \\
\text { MAP } \\
\text { (Mean= 3.625) }\end{array}$ \\
\hline $\begin{array}{c}\text { TURN-BY- } \\
\text { TURN }\end{array}$ & --- & 0.679 & $2.447^{\prime \prime}$ & $2.643^{\prime \prime}$ \\
\hline TEXT & --- & --- & $1.768^{*}$ & $1.964^{\prime \prime}$ \\
\hline $\begin{array}{c}\text { LARGE } \\
\text { MAP }\end{array}$ & --- & --- & --196 \\
\hline
\end{tabular}

$* \mathrm{p}<0.01$

Decision-Time ANOVA. A 2 (age) x 4 (navigational aid) repeated-measures ANOVA performed for decision time revealed main effects for age $(F(1,52)=10.22, p=0.002)$ and navigational aid $(\mathrm{F}(3,156)=63.66, \mathrm{p} .<0.001)$. As expected, the older group's decision time averaged across all aids (mean $=5.18 \mathrm{~s}$ ) was slower than the younger group's time $($ mean $=3.44 \mathrm{~s})$. The pattern of decision time was similar to that of accuracy. Decision time was best with ATIS (mean=2.48 s), followed by the text directions (mean= $2.75 \mathrm{~s})$, the large map (mean= $5.59 \mathrm{~s})$, and the standard map $($ mean $=6.42 \mathrm{~s})$. The average navigational decision time taken by each age group and for each type of navigational aid is shown in figure 4.



Figure 4. Average decision time by age group and navigational aid. 
Newman-Keuls pairwise comparisons of the decision time means using a critical value of 1.18 ( $p<0.01$ ), as shown in table 3, found significant differences between: (1) the large map and the ATIS, (2) the large map and the text directions, (3) the standard map and the ATIS, and (4) the standard map and the text directions.

Table 3. Newman-Keuls pairwise mean comparisons of decision time by navigational aid.

\begin{tabular}{|c|c|c|c|c|}
\cline { 2 - 5 } \multicolumn{1}{c|}{} & $\begin{array}{c}\text { TURN } \\
\text { (Mean= 2.48) }\end{array}$ & $\begin{array}{c}\text { TEXT } \\
\text { (Mean= 2.75) }\end{array}$ & $\begin{array}{c}\text { LARGE MAP } \\
\text { (Mean= 5.59) }\end{array}$ & $\begin{array}{c}\text { STANDARD } \\
\text { MAP } \\
\text { (Mean = 6.42) }\end{array}$ \\
\hline $\begin{array}{c}\text { TURN-BY- } \\
\text { TURN }\end{array}$ & --- & 0.27 & $3.11 ”$ & $3.94 *$ \\
\hline TEXT & --- & --- & $2.84 ”$ & $3.67 ”$ \\
\hline LARGE MAP & --- & --- & -- & 0.83 \\
\hline
\end{tabular}

$* p<0.01$

\section{Cognitive Testing}

The data from the cognitive battery support extensive previous research on age-related reductions in cognitive testing performance, as shown in table 4. Separate 2 (age) x 2 (gender) ANOVA's showed that the younger group performed better than the older group on each test. The only test with a gender effect was the Hidden Words test $(F(1,52)=$ $3.94, \mathrm{p}<0.05)$, where the women $($ mean $=39.21)$ performed better than the men $($ mean= 34.32). Intercorrelation of the test scores is shown in table 5.

Table 4. Results of cognitive testing by gender and age group.

\begin{tabular}{|l|c|c|c|c|c|c|c|c|c|c|}
\cline { 2 - 11 } \multicolumn{1}{c|}{} & \multicolumn{2}{c|}{\begin{tabular}{c} 
Younger \\
\multicolumn{1}{c|}{ Females }
\end{tabular}} & \multicolumn{2}{c|}{$\begin{array}{c}\text { Younger } \\
\text { Males }\end{array}$} & \multicolumn{2}{c|}{$\begin{array}{c}\text { Older } \\
\text { Females }\end{array}$} & \multicolumn{2}{c|}{$\begin{array}{c}\text { Older } \\
\text { Males }\end{array}$} & \multicolumn{2}{c|}{ F (1,52) } \\
\cline { 2 - 12 } & MEAN & S.D. & MEAN & S.D. & MEAN & S.D. & MEAN & S.D. & Age & Gender \\
\hline $\begin{array}{l}\text { Identical } \\
\text { Pictures }\end{array}$ & 34.0 & 6.6 & 31.4 & 5.8 & 24.6 & 5.4 & 22.3 & 5.0 & $36.9^{*}$ & 2.52 \\
\hline $\begin{array}{l}\text { Map } \\
\text { Planning }\end{array}$ & 09.9 & 2.8 & 10.6 & 3.3 & 8.2 & 2.7 & 7.3 & 2.7 & $10.6^{*}$ & 0.03 \\
\hline $\begin{array}{l}\text { Maze } \\
\text { Tracing }\end{array}$ & 11.4 & 3.2 & 11.4 & 3.9 & 6.6 & 2.8 & 7.0 & 2.5 & $30.3^{*}$ & 0.09 \\
\hline $\begin{array}{l}\text { Card } \\
\text { Rotations }\end{array}$ & 49.4 & 20.8 & 42.4 & 13.8 & 33.8 & 15.1 & 32.8 & 13.9 & $8.6^{*}$ & 0.86 \\
\hline $\begin{array}{l}\text { Hidden } \\
\text { Words }\end{array}$ & 39.6 & 9.7 & 39.3 & 9.9 & 38.9 & 7.7 & 29.4 & 9.4 & $4.7^{*}$ & $3.94 *$ \\
\hline p $<0.05$
\end{tabular}


Table 5. Intercorrelation of cognitive test scores.

\begin{tabular}{|l|c|c|c|c|c|}
\cline { 2 - 6 } \multicolumn{1}{c|}{} & $\begin{array}{c}\text { Maze } \\
\text { Tracing } \\
\text { Speed }\end{array}$ & $\begin{array}{c}\text { Card } \\
\text { Rotations }\end{array}$ & $\begin{array}{c}\text { Map } \\
\text { Planning }\end{array}$ & $\begin{array}{c}\text { Identical } \\
\text { Pictures }\end{array}$ & $\begin{array}{c}\text { Hidden } \\
\text { Words }\end{array}$ \\
\hline $\begin{array}{l}\text { Maze Tracing } \\
\text { Speed }\end{array}$ & - & $0.54^{* *}$ & $0.71^{* *}$ & $0.68^{* *}$ & $0.41^{* *}$ \\
\hline $\begin{array}{l}\text { Card } \\
\text { Rotations }\end{array}$ & $0.54^{* *}$ & - & $0.39^{* *}$ & $0.46^{* *}$ & $0.26^{*}$ \\
\hline Map Planning & $0.71^{* *}$ & $0.39^{* *}$ & - & $0.50^{* *}$ & $0.47^{* *}$ \\
\hline $\begin{array}{l}\text { Identical } \\
\text { Pictures }\end{array}$ & $0.68^{* *}$ & $0.46^{* *}$ & $0.50^{* *}$ & - & $0.38^{* *}$ \\
\hline Hidden Words & $0.41^{\prime \prime \prime}$ & $\mathbf{0 . 2 6 ”}$ & $\mathbf{0 . 4 7}, 7^{\prime \prime}$ & $\mathbf{0 . 3 8} 8^{\prime \prime \prime}$ & - \\
\hline
\end{tabular}

$* \mathrm{p}<0.05$

$* * \mathrm{p}<0.01$

\section{Route-Following Performance and Cognitive Scores}

Many of the correlations between the cognitive test scores, accuracy, and decision time are significant, as shown in table 6 . The strong correlations suggest that the cognitive test scores predicted navigational performance. This finding suggests that differences in navigational performance between the older and younger groups were partly due to differences in cognitive ability.

Accuracy ANCOVA. As demonstrated in table 4, the older group performed worse on the spatial ability measures than the younger group. Based on an assumption that the navigational task in the simulator required the ability to process spatial information, it follows that the lower spatial ability in the older group may have explained, to some degree, the group's lower accuracy levels. To examine how the measures of spatial ability predicted performance in terms of accuracy in the navigational task, an analysis of covariance (ANCOVA) was conducted.

An ANCOVA is a statistical tool used to examine group differences in a dependent variable after "removing" the influence of another variable (called the covariate) on the dependent variable. Covariates are selected on the basis of their known, or hypothesized, relationship with the dependent variable. The purpose of an ANCOVA is to adjust for differences in the dependent variable based on the covariate. Thus, an ANCOVA can address the question of whether the differences in navigational performance between the age groups were due to differences in spatial ability or perceptual speed. 
Table 6. Correlations between accuracy, decision time, and cognitive test scores. TEXT DIRECTIONS LARGE MAP

\begin{tabular}{|c|c|cc|cc|}
\hline Construct & $\begin{array}{c}\text { Cognitive } \\
\text { Test }\end{array}$ & Acc & Dec Time & Acc & Dec Time \\
\hline $\begin{array}{c}\text { Spatial } \\
\text { scanning }\end{array}$ & $\begin{array}{c}\text { Maze } \\
\text { Tracing }\end{array}$ & $-0.480^{\prime \prime \prime}$ & $-0.489^{* *}$ & $-0.330^{* *}$ & $-0.387^{* *}$ \\
\hline $\begin{array}{c}\text { Spatial } \\
\text { Scanning }\end{array}$ & $\begin{array}{c}\text { Map } \\
\text { Planning }\end{array}$ & $-0.492^{* *}$ & $-0.449^{* *}$ & $-0.405^{* *}$ & $-0.350^{\prime \prime \prime}$ \\
\hline $\begin{array}{c}\text { Spatial } \\
\text { Orientation }\end{array}$ & $\begin{array}{c}\text { Card } \\
\text { Rotations }\end{array}$ & -0.242 & $-0.316^{\prime \prime}$ & $-0.323^{* *}$ & $-0.476^{* *}$ \\
\hline $\begin{array}{c}\text { Verbal } \\
\text { Closure }\end{array}$ & $\begin{array}{c}\text { Hidden } \\
\text { Words }\end{array}$ & $-0.311^{* *}$ & $-0.525^{* *}$ & -0.216 & $-0.328^{\prime \prime \prime}$ \\
\hline $\begin{array}{c}\text { Perceptual } \\
\text { Speed }\end{array}$ & $\begin{array}{c}\text { Identical } \\
\text { Pictures }\end{array}$ & $-0.328^{* *}$ & $-0.489^{* *}$ & -0.134 & $-0.471^{\prime \prime \prime}$ \\
\hline
\end{tabular}

STANDARD MAP

ATIS

\begin{tabular}{|c|c|c|c|c|c|}
\hline construct & $\begin{array}{c}\text { Cognitive } \\
\text { Test } \\
\end{array}$ & Acc & Dec Time & Acc & Dec Time \\
\hline $\begin{array}{c}\text { Spatial } \\
\text { Scanning }\end{array}$ & $\begin{array}{c}\text { Maze } \\
\text { Tracing }\end{array}$ & $-0.473 * *$ & $-0.454 * *$ & $-0.507 * *$ & $-0.433 * *$ \\
\hline $\begin{array}{c}\text { Spatial } \\
\text { Scanning }\end{array}$ & $\begin{array}{c}\text { Map } \\
\text { Planning }\end{array}$ & $-0.392 * *$ & $-0.414 "$, & $-0.469 * *$ & $-0.367 * *$ \\
\hline $\begin{array}{c}\text { Spatial } \\
\text { Orientation }\end{array}$ & $\begin{array}{c}\text { Card } \\
\text { Rotations }\end{array}$ & $-0.321^{*}$ & $-0.405 " ”$ & $-0.275^{*}$ & $-0.294 ”$ \\
\hline $\begin{array}{c}\text { Verbal } \\
\text { Closure }\end{array}$ & $\begin{array}{l}\text { Hidden } \\
\text { Words }\end{array}$ & $-0.255^{\prime \prime}$ & $-0.420 * *$ & $-0.309 "$ & $-0.380 * *$ \\
\hline $\begin{array}{l}\text { Perceptual } \\
\text { Speed }\end{array}$ & $\begin{array}{l}\text { Identical } \\
\text { Pictures }\end{array}$ & $-0.362 * *$ & $-0.512 * *$ & $-0.560 * *$ & -0.539"'" \\
\hline
\end{tabular}

Spatial ability was used as a covariate in the first ANCOVA because earlier research suggested that a relationship existed between an individual's navigational skill and spatial ability. Similarly, perceptual speed was used as a covariate in the second analysis because earlier research linked decision time with perceptual speed. Thus, the covariate used was the mean of the z-scores for both the Maze Tracing Speed test and the Map Planning test because these were the only tests with significant correlations for accuracy with all navigational aids. A 2 (age) $\mathrm{x} 4$ (navigational aid) ANCOVA revealed a significant main effect for navigational aid $(F(3,51)=19.12, p<0.001)$, but the main effect for age was not significant after the effects of spatial ability were removed. The results suggest that differences in navigational accuracy were due to differences in spatial ability, not age per se. 
Figure 5 illustrates the relationship between spatial ability and navigational accuracy. Individuals were grouped by their spatial covariate score into: (1) high (one or more standard deviations above the mean), (2) average (within one standard deviation), or (3) low (more than one standard deviation below the mean) groups.

Figure 6 illustrates the adjusted accuracy levels after removing the influence of spatial ability. Although the figure shows that the younger group performed worse on the text directions and the large map, it is important to note that the age group differences are not statistically significant The differences in the text directions and the large map that are illustrated in the figure can be interpreted only as random, unexplained error, with no statistical significance.

Decision-Time ANCOVA. As with spatial ability, perceptual speed for the older group was slower than for the younger group, which may explain the differences in navigational decision time between the two age groups. The correlations between the Identical Pictures (perceptual speed) scores and the accuracy scores suggest that perceptual speed, as well as spatial ability, may explain differences in accuracy. To determine if perceptual speed accounted for age differences in accuracy, an ANCOVA was performed using the Identical Pictures score as the covariate. As with the accuracy ANCOVA, the ANCOVA revealed a significant main effect for navigational aid $(\mathrm{F}(3,162)=22.81, \mathrm{p}<\mathrm{O} . \mathrm{OO})$, but not for age. Thus, differences in accuracy were due to differences in perceptual speed and spatial ability. The low correlations between perceptual speed scores and accuracy in the large map and standard paper map conditions suggest that spatial ability accounted for performance differences, more so than did perceptual speed.



Figure 5. Average accuracy by spatial ability group and navigational aid. 


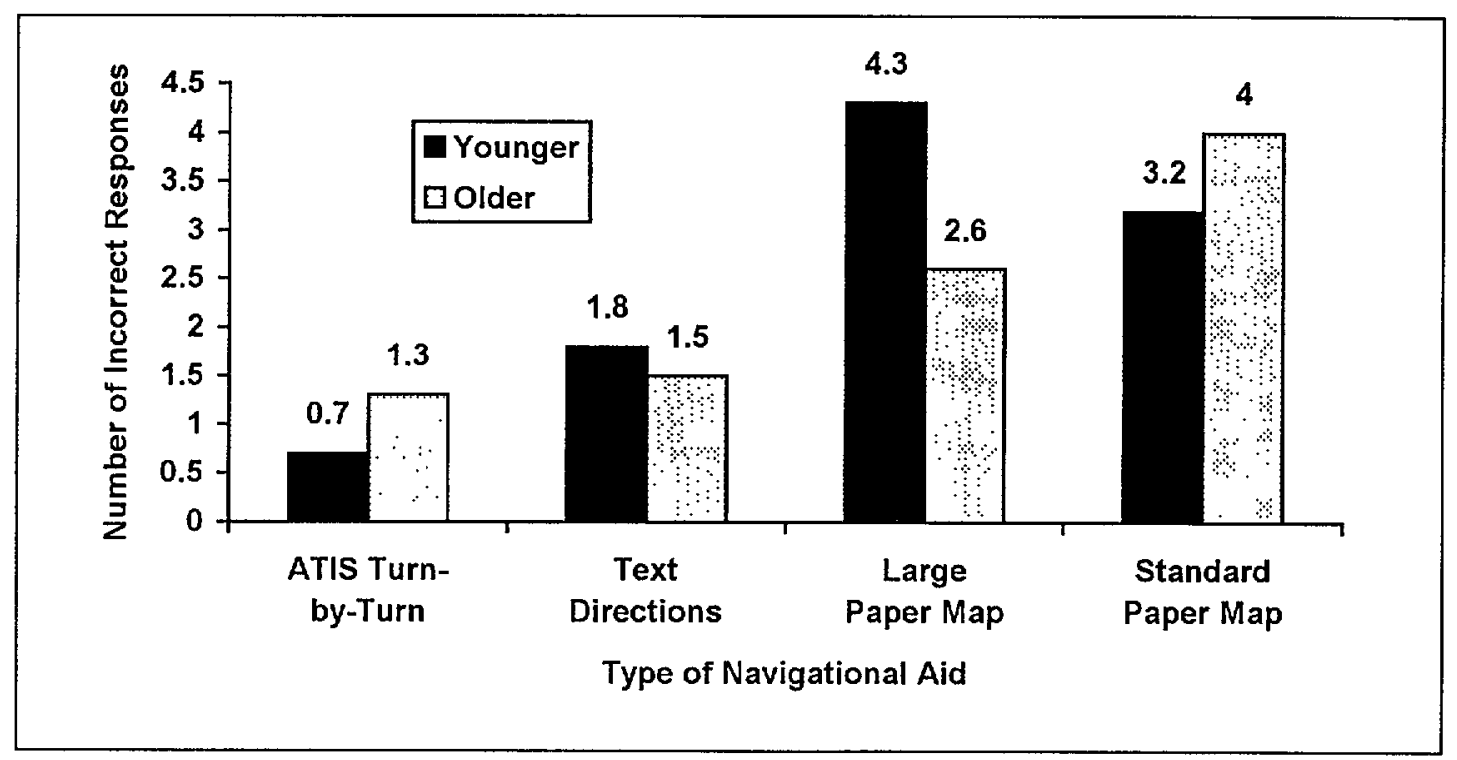

Figure 6. Average accuracy after removing the influence of spatial ability.

An analysis of covariance was used to determine if perceptual speed accounted for decisiontime differences between the age groups. The score for perceptual speed was used as a covariate in a 2 (age) $x 4$ (navigational aid) ANCOVA with decision time as the dependent variable. After removing the influence of perceptual speed, a significant main effect was found for navigational aid $(\underline{\mathrm{F}}(3,162)=64.57, \underline{\mathrm{p}}<0.001)$, but not for age $(\underline{\mathrm{F}}(1,53)=$ $2.58, \mathrm{p}=0.670$ ). Thus, the differences in perceptual speed between the age groups accounted for the differences in decision time. Figure 7 illustrates the average decision time for each navigational aid and age group, after removing the influence of perceptual speed. As in figure 6, the younger group had a mean slower decision time than the older group when using the large paper map. Again, this difference is not statistically significant.

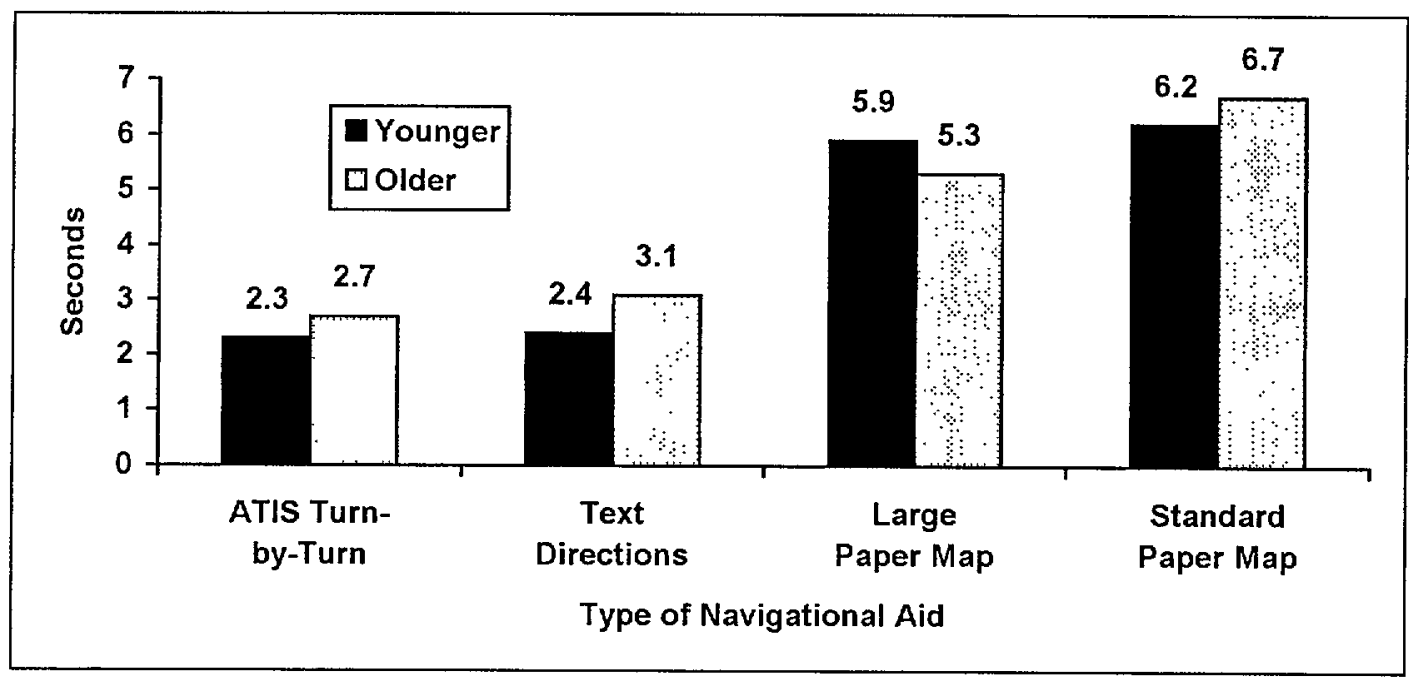

Figure 7. Average decision time after removing the influence of perceptual speed. 
To determine if spatial ability accounted for differences in decision time, an ANCOVA was performed with age as an independent category, type of navigational aid as a within-subjects independent variable, the mean spatial ability z-scores as the covariate (described above), and decision time as the dependent variable. The ANCOVA revealed a significant main effect for navigational aid $(\mathrm{F}(3,156)=39.52, \mathrm{p}<\mathrm{O} . \mathrm{OOO})$, and age $(\mathrm{F}(1,53)=5.15, \mathrm{p}=$ 0.028). This result demonstrates that spatial ability did not account for performance differences in decision time.

Comparison of Correlational Elements. The pattern of the correlations between accuracy and decision time differed across navigational aids, as shown in table 6 . The correlation for ATIS was the highest (0.64), followed by both maps ( 0.43 each), and the text directions (0.34). A statistical technique was used to compare two correlations. ${ }^{(38)}$ The technique tests whether the ATIS accuracy/decision-time correlation was statistically different than the accuracy/decision-time correlation for: (1) each map and (2) the text directions. The correlations for ATIS and for the text directions were significantly different $(\mathrm{Z}=2.345, \mathrm{p}$ $<0.05)$, but the correlations for ATIS were not significantly different from that for either map $(Z=1.59, p>0.05)$. The relationship between accuracy and decision time for ATIS differed from the text directions in that decision-making was more tightly coupled with decision time for ATIS. This suggests that ATIS was easier to use, as it did not require a trade-off between speed and accuracy.

Regression Analyses of Cognitive Scores on Accuracy. A statistical examination of the relationship between the cognitive test data and navigational accuracy and decision time can be used to understand the cognitive processes underlying the use of each navigational aid. A series of simultaneous regression analyses were conducted with the cognitive test scores as predictor variables and accuracy or decision time as dependent variables, as shown in appendix E. The results of the analyses show the unique statistical contribution of each cognitive ability on accuracy and decision time.

Table 7 summarizes the results of the analyses, which show that the test score that uniquely predicted accuracy for the text directions and each paper map was the composite spatial ability score. In contrast, accuracy for the ATIS display was uniquely predicted by the perceptual speed score, and not the spatial ability score. This finding shows that using the ATIS display required perceptual speed more than spatial ability, which suggests that using the ATIS display required little or no interpretation of spatial information. This result corroborates the finding in the previous section on the comparisons of correlation elements. The results of the decision-speed analyses showed that the perceptual speed scores uniquely predicted performance for both the maps and the ATIS display. However, verbal ability scores uniquely predicted decision time for the text directions. 
Table 7. Summary of simultaneous multiple regression results showing the cognitive constructs with significant betas for each navigational aid.

\begin{tabular}{|c|c|c||}
\cline { 2 - 3 } \multicolumn{1}{c}{} & \multicolumn{2}{c|}{ NAVIGATIONAL PERFORMANCE VARIABLES } \\
\cline { 2 - 3 } NAVIGATIONAL AID & ACCURACY & DECISION TIME \\
\hline \hline Text Directions & Spatial Scanning & Verbal Closure \\
\hline Large Map & Spatial Scanning & Perceptual Speed \\
\hline Standard Map & Spatial Scanning & Perceptual Speed \\
\hline ATIS & Perceptual Speed & Perceptual Speed \\
\hline
\end{tabular}

Specific Comparisons: Age and Performance with ATIS. One issue addressed in this study was the extent to which ATIS turn-by-turn route guidance might enhance route-following performance for older drivers. Two measures of the effectiveness of ATIS in facilitating navigation for the older group are the extent to which their accuracy with ATIS improved relative to: (1) their pooled accuracy and decision time with traditional navigational aids and (2) the pooled accuracy and decision time of the younger group with the traditional navigational aids.

To evaluate the statistical difference of these values, specific comparisons were made and compared against a critical F-value derived from the Scheffe method. The results of these comparisons show that the older group made significantly fewer navigational errors $(\mathrm{F}(3,54)=9.26, \mathrm{p}<0.05)$ when using ATIS compared to using the traditional navigational aids. Accuracy for the older group using ATIS was not significantly different than accuracy for the younger group using the traditional aids.

The results of the contrasts using decision time were similar to that of accuracy when using ATIS-the older group had significantly faster decision times than when using traditional aids $(\mathrm{F}(3) 54)=18.86, \mathrm{p}<0.01)$. However, the older group using ATIS did not have statistically different decision times than the younger group using traditional navigational aids. These findings suggest that using ATIS significantly improved the older group's performance over that with traditional aids; but it also suggests that the older group's performance with ATIS was as good as the younger group's performance with traditional navigational aids. In this sense, ATIS has potential as an intervention for older drivers.

\section{Tracking Performance}

Repeated-Measures MANOVA. A 2 (age group) x 2 (gender) x 4 (navigational aid) repeated-measures MANOVA was performed with tracking-error frequency and tracking average error duration as the dependent variables. The MANOVA showed a pattern similar to the accuracy and decision-time MANOVA, with a main effect for age group $(\mathrm{F}(2,51)=$ $13.35, \mathrm{p}<0.001)$, and navigational aid $(\mathrm{F}(6,47)=3.63, \mathrm{p}=0.005)$, but not for gender and no interactions. 
Error-Freauencv ANOVA. A 2 (age) x 4 (navigational aid) repeated-measures ANOVA was performed on tracking-error frequency. Data from three subjects were dropped from this analysis because their scores were more than three standard deviations above the mean. The ANOVA revealed a main effect for age $(\mathrm{F}(1,54)=10.99, \mathrm{p}=0.002)$ and navigational aid $(F(3,52)=2.96, p=0.034)$. As shown in figure 8 , the older group made more tracking errors (mean $=12.08)$ than did the younger group $($ mean $=5.27)$. The fewest errors were made with ATIS (mean= 6.00), followed by the standard map (mean= $7.60)$, the text directions (mean= 7.83), and the large map (mean= 8.04).

Newman-Keuls pair-wise comparisons using a critical value of 1.44 revealed that the tracking errors made with ATIS were less than for all other aids. There were no significant differences between any other navigational aids, as shown in table 8 .

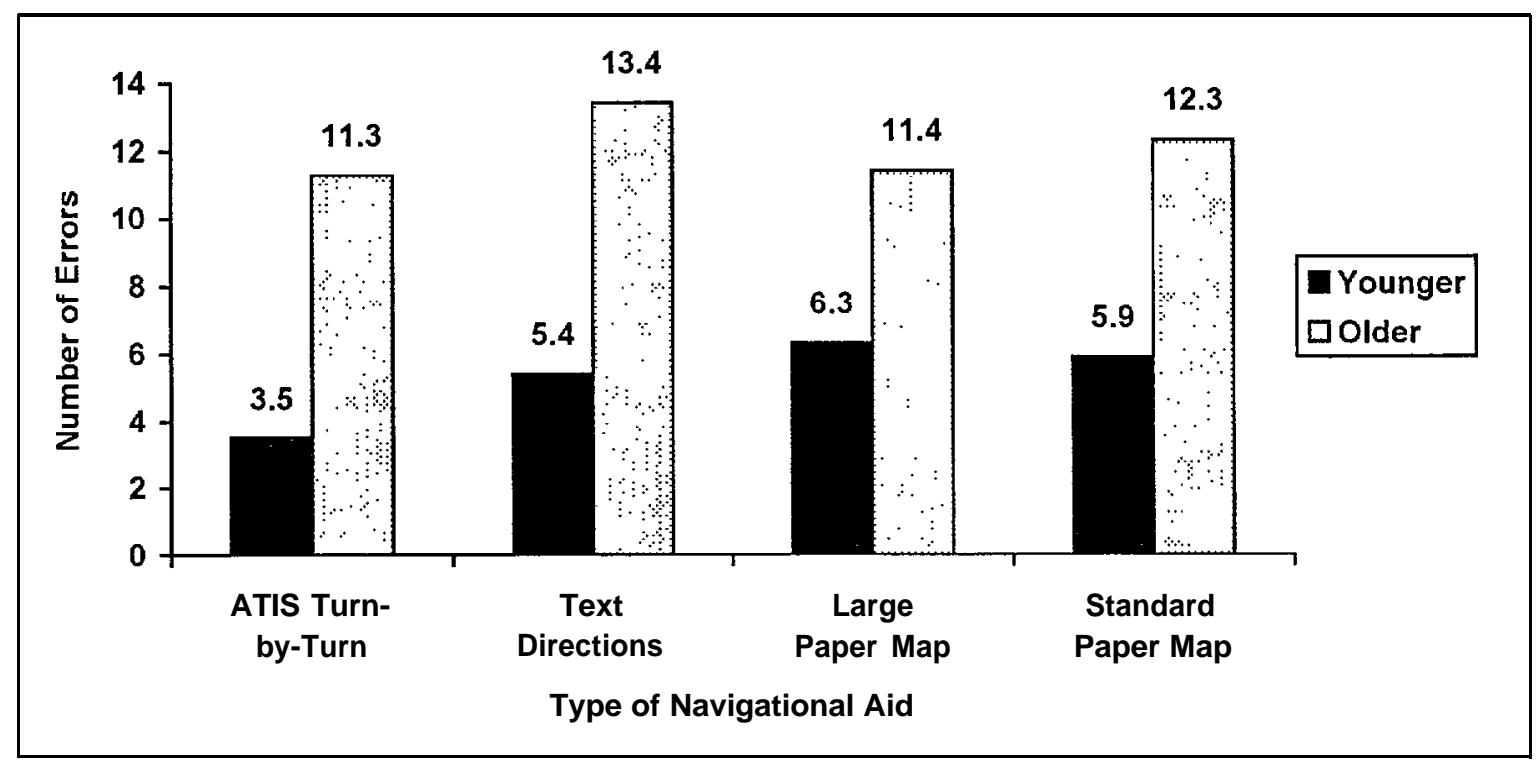

Figure 8. Average number of tracking errors by age group and navigational aid.

Table 8. Newman-Keuls pairwise mean comparisons of tracking-error frequency by navigational aid.

\begin{tabular}{|c|c|c|c|c|}
\cline { 2 - 5 } \multicolumn{1}{c|}{} & $\begin{array}{c}\text { ATIS } \\
\text { (Mean=6.00) }\end{array}$ & $\begin{array}{c}\text { STANDARD } \\
\text { MAP } \\
\text { (Mean=7.60) }\end{array}$ & $\begin{array}{c}\text { TEXT } \\
\text { (Mean=7.83) }\end{array}$ & $\begin{array}{c}\text { LARGE MAP } \\
\text { (Mean=8.04) }\end{array}$ \\
\hline ATIS & --- & $1.60 "$ & $1.83 "$ & $2.04 "$ \\
\hline STANDARD MAP & --- & --- & 0.23 & 0.44 \\
\hline TEXT & ------ & - & 0.21 \\
\hline
\end{tabular}

$* \mathrm{p}<0.05$ 
Average-Error-Duration ANOVA. A 2 (age) x 4 (navigational aid) repeated-measures ANOVA was performed on tracking average error duration. Data from four subjects were dropped from the analysis due to scores three standard deviations above the mean. The ANOVA revealed a main effect for age group $(\underline{F}(1,54)=10.99, \mathrm{p}=0.002)$ and for the navigational aid $(\mathrm{E}(3,52)=2.96, \mathrm{p}=0.034)$. Figure 9 illustrates average error duration by age group and navigational aid. A Newman-Keuls pairwise comparison, shown in table 9 , using a critical value of 0.40 revealed differences between the standard map (mean $=$ 1.37) and ATIS (mean = 0.74), and between the standard map and the large map (mean= 0.95 ). The difference between the standard map and the text directions approached significance-the mean difference was 0.47 , and the F-criterion was $0.48(\mathrm{p}<0.05)$. These results imply that subjects had more trouble correcting their tracking errors when using the standard map. This finding is not surprising, considering that the standard map was typically hand-held.

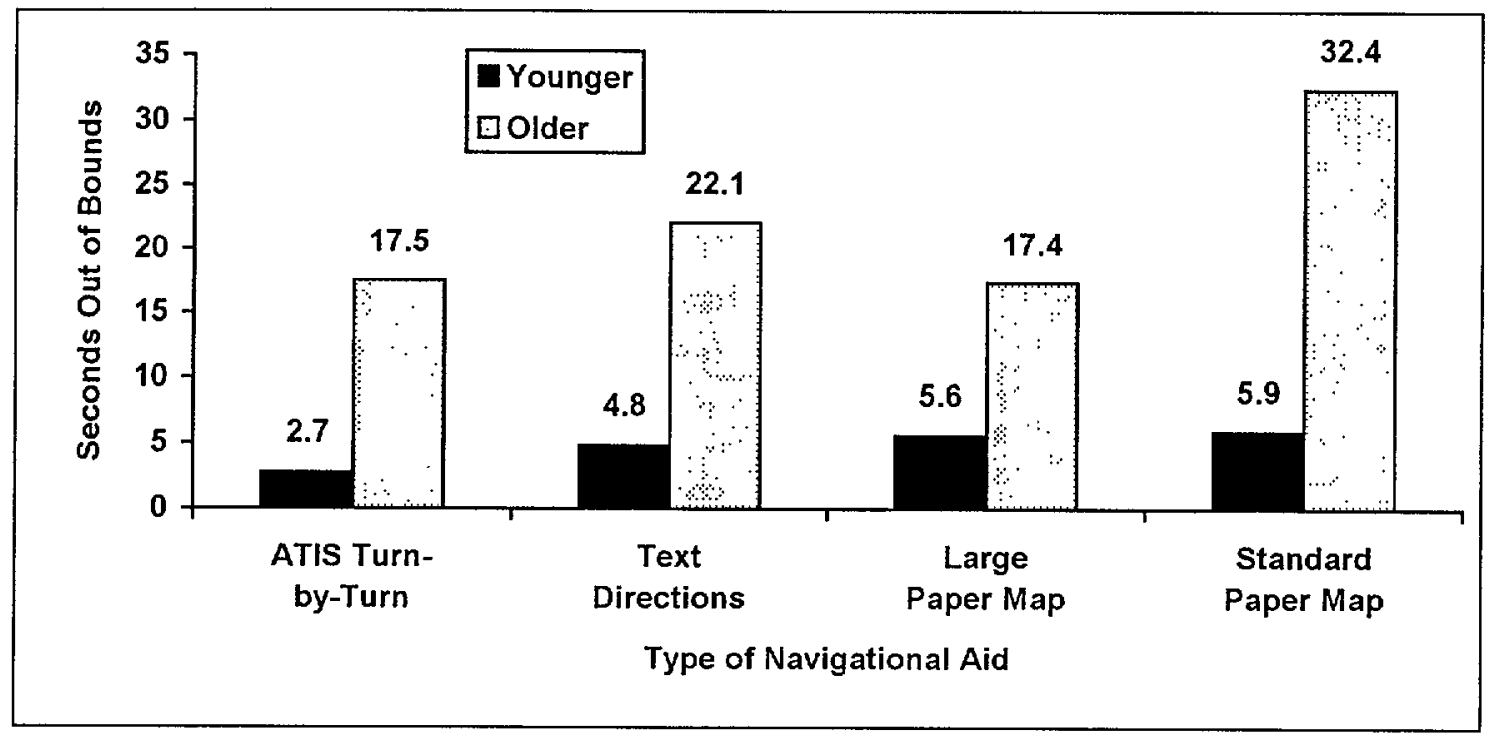

Figure 9. Average duration of tracking error by age group and navigational aid.

Table 9. Newman-Keuls pairwise mean comparisons of average tracking error duration by navigational aid.

\begin{tabular}{|c|c|c|c|c|}
\cline { 2 - 5 } \multicolumn{1}{c|}{} & $\begin{array}{c}\text { ATIS } \\
\text { (Mean }=0.74)\end{array}$ & $\begin{array}{c}\text { TEXT } \\
(\text { Mean }=0.90)\end{array}$ & $\begin{array}{c}\text { LARGE MAP } \\
\text { (Mean =0.95) }\end{array}$ & $\begin{array}{c}\text { STANDARD } \\
\text { MAP } \\
\text { (Mean = 1.37) }\end{array}$ \\
\hline ATIS & --- & 0.16 & 0.21 & $0.63^{*}$ \\
\hline TEXT & --- & --- & 0.05 & $0.47 ?$ \\
\hline LARGE MAP & --- & --- & -- & $0.42^{*}$ \\
\hline
\end{tabular}

$* \mathrm{p}<0.05$

$? \mathrm{p}<0.10$ 


\section{Questionnaire Results}

Data from the questionnaire, the route-following task, and the cognitive battery were analyzed to examine driver preferences for navigational information, and the effect of preference on performance. First, descriptive statistics that summarize subject responses to the questionnaire are presented. Second, the results of a factor analysis of the questionnaire data are presented, followed by a presentation of a series of multiple regression analyses used to analyze the relationship between navigational preference and performance.

Navigational Preference. The statistics described here illustrate the differences between peoples' choice of words or maps, their perceived ability to use maps, and their navigational ability in general as reported on the questionnaire presented in appendix A. Table 10 shows average ratings and standard deviations for preferences for maps, the importance of landmarks when navigating, and how much drivers like finding different ways to get to the same place. Table 11 shows average ratings and standard deviations for perceived navigational ability. For most of these questions, the standard deviations are smaller in the older group because the older group had a relatively narrow range of responses. For example, most older subjects rated their ability in map-reading from average to excellent, while younger subject answers ranged from poor to excellent.

Table 10. Preference ratings and standard deviations by gender and age group.

\begin{tabular}{|c|c|c|c|}
\hline $\begin{array}{c}\text { Groups } \\
(\mathrm{N}=14 \text { each) }\end{array}$ & Like Using Maps & $\begin{array}{c}\text { Importance of } \\
\text { Landmarks }\end{array}$ & $\begin{array}{c}\text { Like Finding } \\
\text { Different Ways }\end{array}$ \\
\hline Younger Females & $3.21 \quad(1.72)$ & $\begin{array}{ll}4.50 & (0.94)\end{array}$ & $3.79(1.37)$ \\
\hline Younger Males & $3.64(1.60)$ & $4.71 \quad(0.47)$ & $4.21 \quad(1.12)$ \\
\hline Older Females & $4.36(1.01)$ & $4.43(0.76)$ & $4.07 \quad(1.14)$ \\
\hline Older Males & $4.64(0.50)$ & $3.79(1.12)$ & $3.79(0.89)$ \\
\hline
\end{tabular}

Table 11. Perceived ability ratings and standard deviations by gender and age group.

\begin{tabular}{|l|c|c|c|}
\hline $\begin{array}{c}\text { Groups } \\
(\mathrm{N}=14 \text { each) }\end{array}$ & $\begin{array}{c}\text { Ability to Locate } \\
\text { Position on Map }\end{array}$ & $\begin{array}{c}\text { Easy for You to } \\
\text { Learn New Roads }\end{array}$ & $\begin{array}{c}\text { Rate Your Sense of } \\
\text { Direction }\end{array}$ \\
\hline Younger Females & $3.21(3.21)$ & $3.64(1.45)$ & $3.21(1.25)$ \\
\hline Youngcr Males & $3.93(1.07)$ & $3.86(0.95)$ & $3.71(1.27)$ \\
\hline Older Females & $3.79(0.80)$ & $3.57(0.94)$ & $3.21(1.05)$ \\
\hline Older Males & $4.36(0.63)$ & $3.71(0.73)$ & $3.79(0.97)$ \\
\hline
\end{tabular}

Tables 12 and 13 show the percentage of subjects who preferred receiving and giving (respectively) verbal directions and maps. While most subjects prefer maps for directions over words, less than 15 percent of the females and nearly half of the males usually give maps for directions. 
Table 12. Percentage preferring to get directions in words or maps by gender and age group.

\begin{tabular}{|l|c|c|c|}
\hline \multicolumn{1}{|c|}{ Ouestion: } & \multicolumn{3}{|c|}{ Would You Rather Get Directions in: } \\
\hline $\begin{array}{c}\text { Groups } \\
\text { (N=14 each) }\end{array}$ & Words & Map & Either One \\
\hline Younger Females & $29 \%$ & $64 \%$ & $7 \%$ \\
\hline Younger Males & $21 \%$ & $64 \%$ & $14 \%$ \\
\hline Older Females & $7 \%$ & $79 \%$ & $14 \%$ \\
\hline Older Males & $0 \%$ & $79 \%$ & $21 \%$ \\
\hline
\end{tabular}

Table 13. Percentage preferring to give directions in words or maps by gender and age group.

\begin{tabular}{|l|c|c|c|}
\hline \multicolumn{1}{|c|}{ Question: } & \multicolumn{3}{|c|}{ Do You Usually Give Directions in: } \\
\hline $\begin{array}{c}\text { Groups } \\
\text { (N=14 each) }\end{array}$ & Words & Map & Either One \\
\hline Younger Females & $50 \%$ & $14 \%$ & $36 \%$ \\
\hline Younger Males & $29 \%$ & $43 \%$ & $29 \%$ \\
\hline Older Females & $43 \%$ & $14 \%$ & $43 \%$ \\
\hline Older Males & $29 \%$ & $36 \%$ & $36 \%$ \\
\hline
\end{tabular}

Figure 10 shows the percentage of all subjects preferring to get directions in words or a map, and figure 11 shows the percentage who give directions in words or a map. There was an inconsistency between how subjects would like to receive directions and how subjects prefer to give directions. When giving directions, subjects did not have a preferred format, but more subjects indicated that they prefer a map to words when receiving directions $\left(\mathrm{x}^{2}(2)=36.57, \mathrm{p}<0.001\right)$. This finding is interesting because while some subjects did perform well when using a map, many subjects did not. 


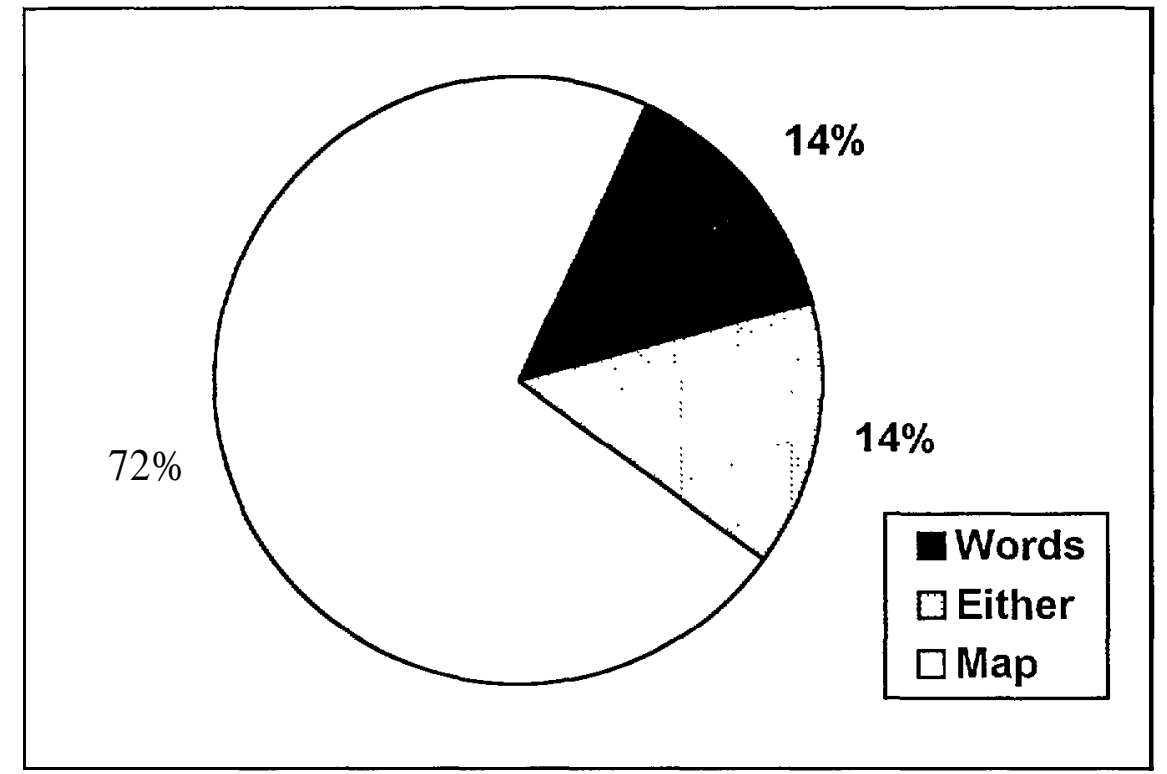

Figure 10. Breakdown of driver preferences for receiving directions.



Figure 11. Breakdown of driver preferences for giving directions.

Factor Analysis. The navigational questionnaire was designed to obtain measures of selfappraisal of navigational ability, map-reading, and preference for maps. A factor analysis of the questionnaire items was conducted to examine whether the questionnaire tapped underlying dimensions of navigational preferences and perceived abilities. First, a principal-axis extraction analysis was used with a varimax rotation. Second, questions with weak contributions to a factor (i.e., loading factors less than 0.40 ) or questions that loaded 
only on factors with eigenvalues less than 1.00 were dropped from subsequent analyses. Third, the remaining eight questions were factor analyzed again, resulting in a two-factor solution. Fourth, two factor analyses were conducted with the remaining eight questions, one for each age group, which confirmed that the solution applied to both younger and older subjects. Table 14 shows the two-factor solution and the factor loadings for each age group.

The first factor was labeled "way-finding" because it is comprised of questions that focus on the ability to navigate in general, in contrast to specific abilities such as map-reading. There is one question in this factor that refers to verbal directions; however, it also asks subjects to rate their ability to navigate in unfamiliar places. The second factor was labeled "preference for maps" and it summarizes subjects' perceived map-reading ability and the extent to which they like using maps.

An ANOVA was performed with gender and age as the independent variables, and each factor score as the dependent variable. No effects were found for the "wayfinding," but a main effect for gender was found in "preference for maps"; males had higher "preference for maps" scores than did females $(\mathrm{F}(1,52)=6.55, \mathrm{p}<0.0130)$. As a group, males liked maps more and rated their map-reading ability higher than did females (demonstrated by the ANOVA results). However, no statistically significant gender difference was found in route-following performance with maps, which suggests that males overrate, or females underrate, their map-reading ability.

Correlations. The data suggest that an individual's perceived wayfinding skills and map preferences are predictive of route-following performance, as shown in table 15. Many of the correlations between the factor scores and accuracy and decision time are strong, which suggests that individuals were generally good at rating their navigational skills.

Hierarchical Regression. A regression model was used to determine the extent to which "wayfinding" and "preference for maps" predicted navigational performance over and above age, gender, and the cognitive test scores for each aid. A hierarchical regression analysis was chosen because the solution isolates the unique contribution of each variable. The variables were entered into the equation in order of presumed causality. Thus, age group and gender were entered first. Perceptual speed scores were entered in the second step because it was viewed as an underpinning to other cognitive skills. In the third step, the mean score for spatial scanning (computed from the Maze Tracing Speed and the Map Planning tests) was entered in the third step. (The score for spatial rotation was dropped because of its multicollinearity effects with spatial scanning scores.) The factor scores for "wayfinding" and "preference for maps" were entered in the last step. 
Table 14. Factor loadings for principal-axis extraction and varimax rotation resulting in a two-factor solution.

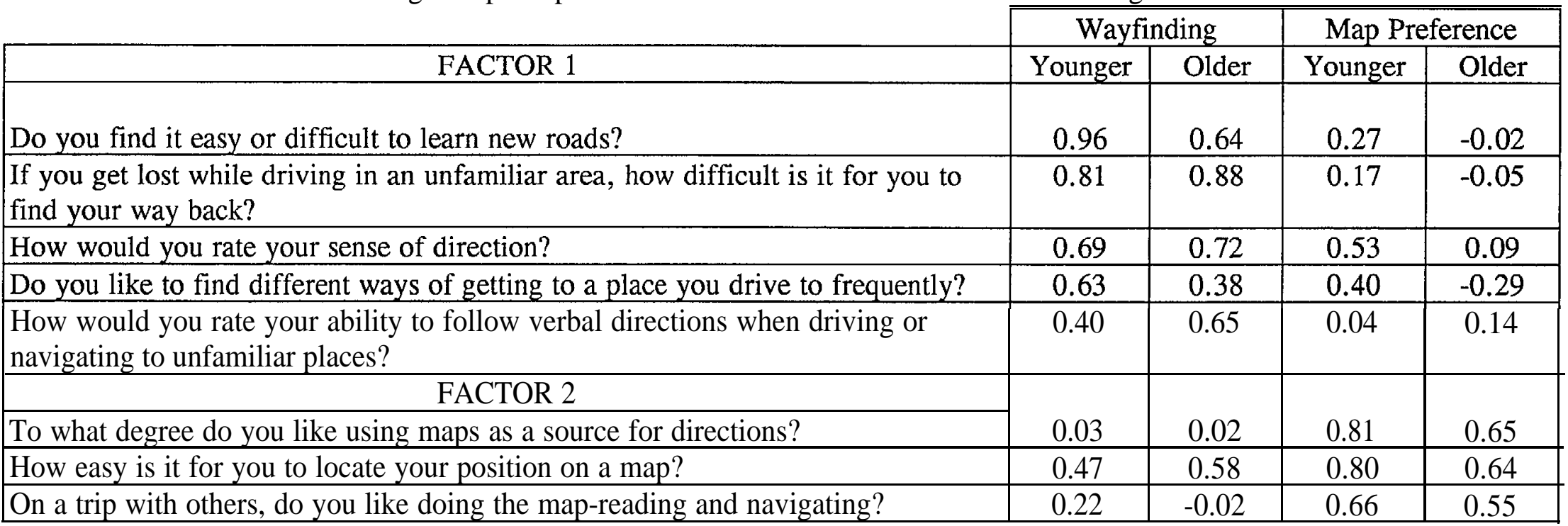

Table 15. Correlational matrix of factor scores, accuracy, and decision time.

BOTH YOUNGER AND OLDER $(\mathrm{N}=56)$

\begin{tabular}{|c|c|c|c|c|c|c|c|c|c|c|}
\hline & \multicolumn{4}{|c|}{ ACCURACY } & \multicolumn{4}{|c|}{ REACTION TIME } & \multicolumn{2}{|c|}{ OVERALL } \\
\hline & TEXT & $\begin{array}{l}\text { LARGE } \\
\text { MAP }\end{array}$ & $\begin{array}{c}\text { STANDAR } \\
\text { MAP }\end{array}$ & ATIS & TEXT & $\begin{array}{c}\text { ARGE } \\
\text { MAP }\end{array}$ & \begin{tabular}{|c|} 
TANDARD \\
MAP \\
\end{tabular} & ATIS & CCURACY & $\begin{array}{c}\text { DECISION } \\
\text { TIME }\end{array}$ \\
\hline WAYFINDING & -0.15 & -0.17 & 0.02 & 0.13 & 0.16 & 0.19 & 0.23 & 0.19 & -0.07 & 0.23 \\
\hline $\begin{array}{l}\text { PREFERENCE } \\
\text { FOR MAPS }\end{array}$ & -0.21 & $-0.55^{* *}$ & $-0.41 * *$ & -0.06 & -0.16 & $-0.34 * *$ & $-0.23 * *$ & -0.06 & $-0.48 * *$ & $-0.26 "$ \\
\hline
\end{tabular}

$* \mathrm{p}<0.01$

$* * \mathrm{p}<0.05$ 
The results of the regression analyses, summarized in table 16, show that the spatial scanning score predicted navigational accuracy for each navigational aid. (Appendix F has the tables for each analysis.) This finding demonstrates that the route-following task required the ability to process spatial information. Also, the factor "preference for maps" had predictive power, but only in the map conditions. Thus, a stronger preference for maps led to better performance with maps.

Table 16. Summary of hierarchical regression results for accuracy.

\begin{tabular}{|l|c|l|}
\hline \multicolumn{1}{|c|}{ NAVIGATIONAL AID } & $\mathrm{R}^{2}$ & Variables with Significant Betas \\
\hline Text Directions & $0.33^{*}$ & Spatial Scanning Score \\
\hline Large Map & $0.50^{*}$ & $\begin{array}{l}\text { Spatial Scanning Score; } \\
\text { "Preference for Maps" }\end{array}$ \\
\hline Paper Map & $0.36^{*}$ & $\begin{array}{l}\text { Spatial Scanning Score; } \\
\text { "Preference for Maps" }\end{array}$ \\
\hline ATIS & $0.50^{*}$ & Spatial Scanning Score \\
\hline
\end{tabular}

$* \mathrm{p}<0.05$

\section{DISCUSSION}

The following is a summary and discussion of the results of this research in terms of: (1) an evaluation of the influence of navigation information on route-following performance and (2) an assessment of the effects of age and spatial ability on navigational performance.

\section{Type of Navigational Aid}

Route-following ability was affected by the type of navigational aid for both age groups and for drivers across a range of cognitive skills. People followed the route more accurately and more quickly when they used ATIS and the text directions compared to when they used the maps. The accuracy scores and decision times with ATIS were consistently better than with text directions, but there was no statistical difference between them. However, the navigational task used here had relatively simple routes, with little traffic, and an easily discernible layout of cross streets. As a result, the routes were amenable to the text directions; however, more complex routes may present greater difficulty with the text directions. For example, increased traffic or confusing street configurations may have made counting the number of blocks until the next turn more difficult than it was for the routes used in this study. In more complex or distracting task situations, ATIS is likely to be superior to text directions. Furthermore, the results of the statistical test comparing the ATIS accuracy/decision time correlation and the text directions accuracy/decision time correlation suggests that the processes or functions involved when using ATIS are different than those used for following text directions. The strong correlation between accuracy and 
decision time with ATIS indicates that decision-making with ATIS is analogous to performing simple decision time tasks.

Although performance was better with ATIS and the text directions, each navigational aid had its own advantages and disadvantages, and emphasized certain aspects of the route. Using the maps was more difficult because it required the ability to judge distances, match intersections on the map to the real world, determine the number of blocks (and distance) until the next turn, maintain a sense of direction, find street names in a complex visual field, and mentally or physically rotate the map so that the direction was congruent with the forward view. These requirements accentuate performance differences due to map-reading ability and spatial ability, such that low-spatial-ability individuals were more likely to read maps poorly and get lost (see references 30 and 32).

In contrast, both the text directions and the turn-by-turn display presented condensed, simplified route information. The text directions were a linear list of street names, devoid of spatial information. The subject used this information to follow a sequence of turns by counting the cross streets until the turn was reached. The turn-by-turn display used a distance meter informing the subject of the proximity of the turn. The subject was not required to count streets to determine where the turn was, but only to monitor the distance meter (when the display ticked down to " 0.0 " the turn-to street was reached). Also, the display had redundant characteristics: the turn indicators were depicted in words and an arrow, and distance was represented graphically as well as with a number. Thus, using ATIS reduced navigation to a simpler task.

\section{Driver Differences}

Spatial Abilitv. The results from this study show that spatial ability predicted navigational ability, regardless of the type of navigational aid used. Specifically, greater spatial ability led to more accurate route-following with the text directions, both maps, and the ATIS display. The strong relationship between spatial ability and navigational accuracy supports the view that navigation involves processing spatial information. For example, when following a route, a driver must identify the route's relevant features from the real world and compare them to their representations from a navigational aid, or vice versa. ${ }^{(29)}$ The capability to: (1) interpret navigational information, (2) search the environment for relevant features (which are often spatial, such as roadway geometry), (3) match route features between the real world and the navigational aid, and (4) estimate time and distance will largely depend on the driver's capacity and efficiency when processing spatial information.

Previous research on the information-processing demands of the driving task has singled out processes of attention, perception, and decision-making. ${ }^{(39)}$ The results from the current study demonstrate that spatial ability is another important component influencing driving capability. Less capacity to process spatial information will lead to inefficiencies when driving. It also follows that navigational aids that present information that is easily matched to the route, such as turn-by-turn displays, will facilitate navigational decision-making. 
Individuals in the current study varied considerably in their spatial ability test scores and their navigational performance. This finding corroborates psychometric research that characterizes individuals as varying widely in their ability to solve spatial problems. The implication of this finding is that the need for ATIS route guidance in the driving population will differ widely in terms of the type of information displayed and the degree of assistance required. Specifically, individuals with low spatial ability may especially benefit from invehicle guidance.

Age Differences. The present data support previous research documenting a global reduction in cognitive resources that accompanies aging and leads to decrements in cognition and perception. $(9,14)$ The older group performed worse than the younger group on most of the dependent measures, including the cognitive battery and the route-following. The only exception was that the older female group scored as well as the younger group on the verbal ability test.

The finding that spatial ability was a predictor of navigational skill helps explain the performance differences between the older and younger age groups. The older group had significantly lower mean spatial ability scores, as well as poorer navigational performance. The differences in spatial ability between the age groups accounted for the differences in navigational accuracy, as demonstrated by the results of the analysis of covariance. The older group's lower spatial ability was likely to affect their sense of direction, spatial orientation, and map-reading abilities during the navigational task. Similarly, the age group differences in perceptual speed explained part of the age effect found in both decision time and accuracy. However, the age effect on decision time remained after differences due to spatial ability were removed, as demonstrated by the analysis of covariance. Thus, unlike the case for accuracy, the factors underlying decision time involved more than spatial ability.

Navigational Preference. The results from this study suggest that people differed in their preferred type of navigational information, and that preferences were predictive of performance. In addition, people were relatively accurate in their assessment of their navigational ability. Specifically, "preference for maps," which summarized perceived map-reading ability and preference for maps, significantly predicted performance with maps over and above that of the cognitive ability measures. Thus, an individual's preference appears to be an important component of performance. This finding corroborates previous work regarding the relevance of navigational preference on performance. ${ }^{(33)}$ However, in terms of performance, ATIS proved to be the superior aid regardless of what preference people had. That is, ATIS mitigated the effects of preference on performance and, in this respect, it outperformed the maps and paper directions. 


\section{Limitations of Study}

It is important to note that aspects of this study may reduce the generalizability of its results. Most younger subjects had attained college or graduate degrees, which suggests that their cognitive test scores may be higher than average. Also, subjects in the older group were likely to represent active, functional, older drivers, and may not represent the majority of older drivers. The routes provided a level of workload and fidelity that limits generalizability. For example, the routes used in the navigational task were short and relatively simple, with low traffic density and clear streets. More complex or longer routes may have highlighted the effects of the navigational aids more so than did the routes used in this task. In addition, the tracking task was set at one rate; when driving in the real world, the difficulty of controlling the vehicle varies with traffic density, type of road, time of day and weather conditions, driver fatigue, etc. Performance with navigational aids will likely change as attention to vehicle control changes. Finally, the ATIS display was based on the TravTek system, and other types of displays may produce different results in terms of accuracy and decision times.

\section{Summary}

Navigational skill was influenced by spatial ability, perceptual speed, and the type of navigational aid. The relatively poor navigational performance of the older group was attributable to their slower perceptual speed and lower spatial ability. Age-related decrements in cognitive abilities imply that there is an incompatibility between older drivers and the highway environment. In this context, ATIS route guidance may be viewed as an intervention aimed at improving highway safety for all drivers, including older drivers, due to its potential to improve driver navigation.

The challenge is to modify existing systems or introduce new ones, such as ATIS route guidance, that enable older drivers to drive safely and efficiently. Older drivers may constitute the group that has the greatest need for, and the most to gain from, in-vehicle route guidance. Further evaluations of ATIS route guidance would benefit by determining the features and characteristics that further simplify the navigational task, particularly for older drivers. 


\section{Driver Navigation Questionnaire}

Circle the number from 1 to 5 that best fits vour answer for each auestion.

How much do you rely on street names when driving someplace new?

On a trip with others, do you like doing the map-reading and navigating?

To what degree do you like using maps as a source for directions?

Not Much

Somewhat

Very Muchı

\begin{tabular}{|lll|} 
& & \\
\hline Not Much & Somewhat & $:$ \\
& & Very Much
\end{tabular}

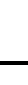

\begin{tabular}{|ccccc|} 
Not Much & & Somewhat & & Very Much \\
\hline 1 & 2 & 3 & 4 & 5
\end{tabular}

How easy is it for you to find different ways of getting to the same place when driving without a map?



How would you rate your ability to follow verbal directions when driving or navigating to unfamiliar places?

When giving directions to someone in person, do you usually give directions in words OR draw a map?

When driving someplace new, would you rather someone gave you verbal directions OR drew you a map?

How important to you are landmarks, such as shopping centers and gas stations, when you are driving someplace new? 
Do you like to find different ways of getting to a place you drive to frequently?

\begin{tabular}{|lcccc} 
Not at All & & 'Sometimes & & Like A Lott \\
& & & & \\
\hline 1 & 2 & 3 & 4 & 5
\end{tabular}

How would you rate your ability to select a routefrom a map in a new area?

(

\begin{tabular}{ccccc} 
Poor & & Average & & Excellent \\
\hline 1 & 2 & 3 & 4 & 5
\end{tabular}

How easy is it for you to locate your position on a map?

\begin{tabular}{|ccccc|} 
Difficult & & Neither & & Easy \\
\hline 1 & 2 & 3 & 4 & 5
\end{tabular}

When stuck in a serious traffic jam, how likely are you to attempt an alternate route to your destination?

Do you find it easy or difficult to learn the roads in a new neighborhood?

Do you get lost while driving in an unfamiliar area, how difficult is it for you to find your way back?

\begin{tabular}{|ccccc|} 
Not at All & \multicolumn{3}{c}{ Somewhat } & Very Likely \\
\hline 1 & 2 & 3 & 4 & 5
\end{tabular}

\begin{tabular}{|ccccc|} 
Difficult & & Neither & & Easy \\
\hline 1 & 2 & 3 & 4 & 5
\end{tabular}

How easy is it for you to give verbal directions off the cuff to someone who is driving to your home from out of town?

\begin{tabular}{|ccccc|} 
Difficult & & Neither & & Easy \\
\hline 1 & 2 & 3 & 4 & 5
\end{tabular}

How would you rate your sense of direction?

\begin{tabular}{|ccccc|} 
Difficult & & Neither & & Easy \\
\hline 1 & 2 & 3 & 4 & 5 \\
Poor & & Average & & Excellent \\
\hline 1 & 2 & 3 & 4 & 5 \\
\hline
\end{tabular}




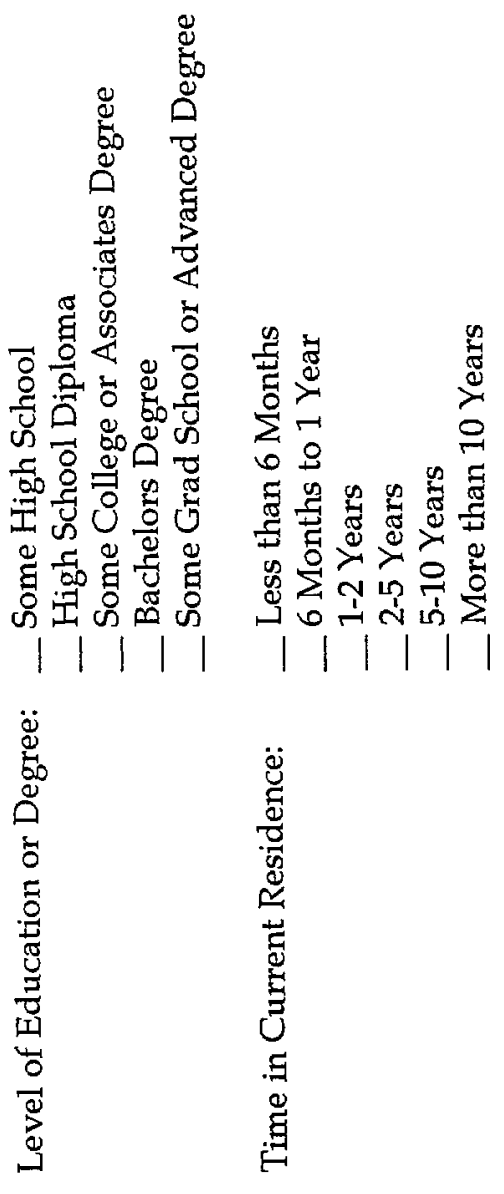




\section{APPENDIX B. SUBJECT INSTRUCTIONS}

This part of the experiment has a practice session, and then a test session. First, I will read to you instructions for the practice session.

\section{[Seat subject in driving buck.]}

There will be two things that you will be asked to do here. You will use the steering wheel to track a red light that moves back and forth on the black part of the front t.v. This is called tracking. You will also watch a videotape of a route from the driver's perspective, and will follow the course of the route by using a navigation aid.

\section{[Tracking Practice]}

First, you will practice tracking. The red light is generated by a laser, which is located above the driver's seat. Please never look directly at the laser.

You will use the steering wheel to keep the red light within the white bounds. A tone will sound when the light goes out of bounds and will turn off when the light is moved back within bounds. Do you have any questions? I will start the laser now for you to practice.

\section{[Set rate at 33 \& play for 2 minutes.]}

\section{[After tracking.]}

Do you have any questions about tracking?

Now I will describe in more detail the second part of the task. You will be given a navigation aid to use as the roadway videotape is playing. The videotape will pause occasionally just before an intersection. During the pause, you should indicate which way you think the car should go by pressing a key on the pad behind the steering wheel. You will base your decision on the navigation aid that you will be using at the time. Press the top key if you think the car should go straight, the left key if left, and the right key if right. During the pause, the red light will stop moving so you won't have to track at that time. Once you press the key, the street names will be shown on the screen. You can use the street names to confirm your choice. After the street names pop up, press one of the keys again. You can make the same choice, or change your choice. After you make the 2nd choice, the tape will resume play. You will use 4 navigation aids today, including a standard paper map, a large map that is mounted on the small t.v., text directions, and a moving guidance display shown on the small t.v.

To summarize, the tape will pause now and then, and you must press a key to indicate which way you think the car should go. After you press a key, street names will appear on the screen. After the street names appear, press a key again, and the tape will resume play. I would like to emphasize that the only time you should press a button is after the tape has 
been paused. Sometimes, after you have pressed the buttons, the tape will look as if it hasn't started. But that can be due to the fact that the car was sitting at a stop sign and had to wait for traffic to pass.

Before we begin, I'd like to point out that the steering that you will perform during tracking will have no correlation with the traffic or turns on the videotape. This might be confusing at first but you will get used to it.

Any questions?

[Show the assigned navigation aid; start practice program.]

[For the paper map.] This time you will use a standard street map. The route has been highlighted. The route begins at the "S." You can hold this map if you wish.

[For the large, mounted paper map.] This time you will use an paper map, with the route highlighted. The route begins at the "S." It will be mounted on the small t.v. Please do not remove the map at any time.

[For the text directions.] This time you will use text directions. The directions are based on the number of blocks \& street names to describe the route, and will be mounted on the small t.v.

\section{[For the guidance display instructions.]}

At this point you will use a moving guidance display that will be shown on the small t.v. This paper describes how to use it. Please read this now, and let me know when you are finished. Feel free to ask any questions.

\section{[After the practice, subject can take a break.]}

\section{[Route-following test session.]}

Now we'll begin the actual test session. The procedure is the same as the practice, except that the routes are a little longer. You will have 1 minute to study the navigation aid before the roadway videotape begins play. You will be tracking as well.

After you use each navigation aid, please fill out the evaluation form for that navigation aid placed on top of the dashboard. There is one form for each aid. The forms will be in a pile, and the top sheet should be the form for the aid you just used. Please rank the navigation aids in the order that you liked them on the last sheet in the pile. 


\section{Route Guidance Display}

The guidance display will provide turn-by-turn directions that match the route shown on the forward screen. The directions look like this:

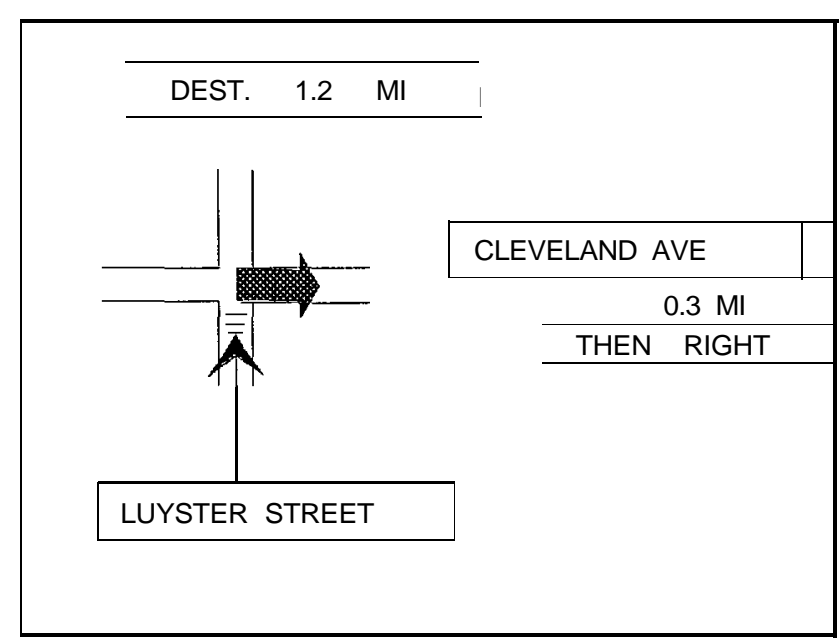

The top box shows the number of miles to go before the destination.

The side box holds the name of the street for your next turn.

The bottom box is the name of the street that you are driving on. Each bar on the picture of Luyster street represents 0.1 mile. In this case, you are on Luyster Street, and in 0.3 mile you should turn right on Cleveland Avenue.

As you travel 0.1 mile, 1 bar will drop out and the arrow will move up. When you have traveled 0.3 mile, the last bar will drop out, and "0.1 MI" under Cleveland Ave will change to "0.0" as shown here:

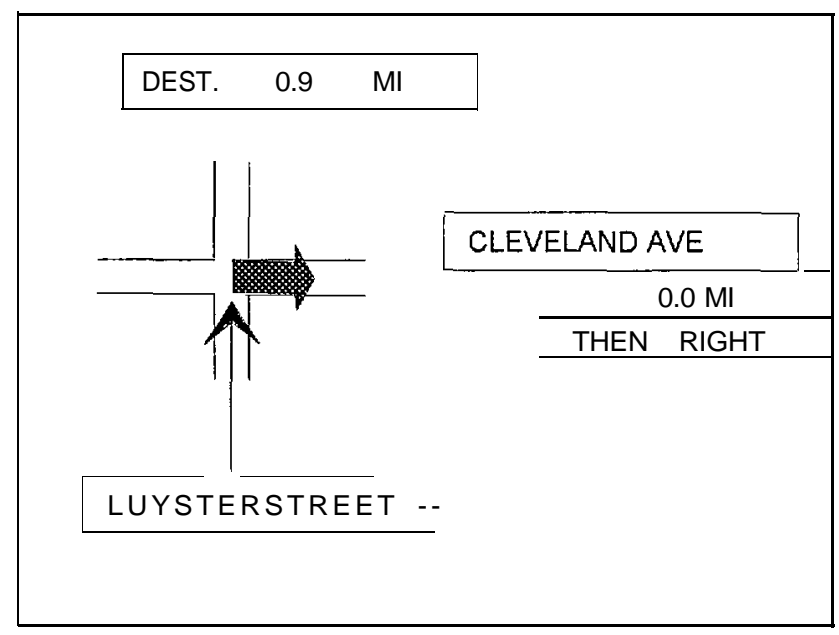

When the number under this street name changes to 0.0 , you have reached the street onto which you should turn. 
After the turn is made, the display will be updated, reflecting the new street and the next turn. In this case, after you turn onto Cleveland Avenue, the display will look like this:

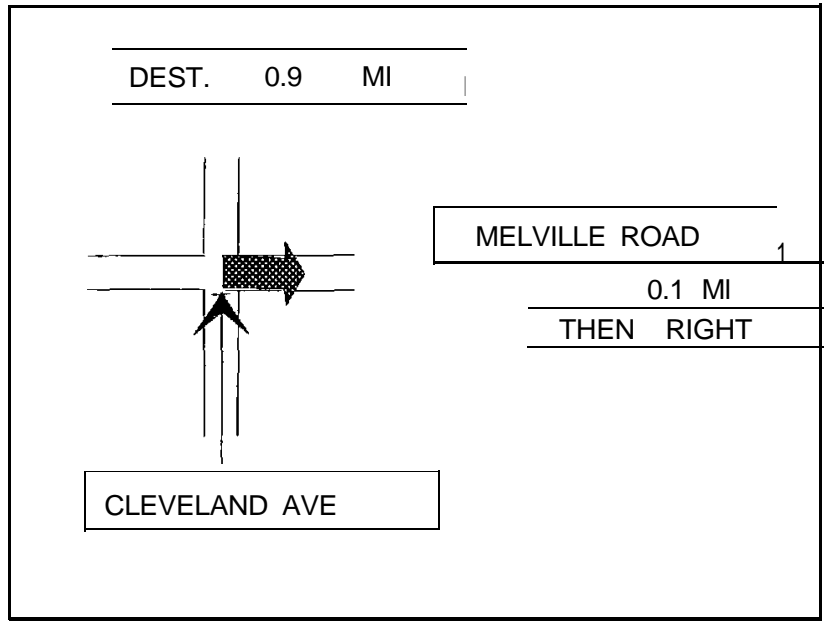

Your next turn is a right onto Melville Road in about 0.1 mile.

Now you are on Cleveland Ave. 


\section{APPENDIX D. ANALYSES OF RESPONSES 1 AND 2}

Separate analyses of the first and second responses were conducted in order to determine if performance differed for each response. Correlations were computed to assess the degree of similarity between the responses. The responses were highly correlated for both accuracy $(\mathrm{r}=0.73, \mathrm{p}<0.001)$ and decision time $(\mathrm{r}=0.65, \mathrm{p}<0.001)$. This result suggests that decision-making for the first response was similar to that for the second response. Figure 12 shows accuracy and figure 13 shows the results for decision time for responses 1 and 2, by age group and navigational aid. As the figures show, both younger and older subjects improved their accuracy and decision times for each navigational aid by the second response.

In order to confirm that the independent variables-age, gender, and the type of navigational aid-had the same effects on accuracy and decision time for both responses, separate repeated-measures MANOVA's were performed for each response. A 2 (age) x 2 (gender) $\mathrm{x} 4$ (navigational aid) repeated-measures MANOVA, with accuracy for the first response as the dependent variable, showed a significant main effect for age $(F(1) 52)=8.05, p=$ $0.006)$ and navigational aid $(F(3,156)=40.32, \mathrm{p}<0.001)$, but not for gender $(\mathrm{F}(1,52)$ $=0.00, \mathrm{p}=1.000)$. The same analysis applied to decision time yielded the same pattern of results: a main effect was found for age $(F(1,52)=15.17, p<0.001)$ and navigational aid $(F(3,156)=39.52, p<0.001)$, but not for gender $(F(1,52)=0.45, p$ $=0.504)$.

Results of the MANOVA on accuracy for the second response showed that there remained a main effect for navigational aid $(\mathrm{F}(3,156)=9.99, \mathrm{p}<0.001)$, but not for age $(\mathrm{F}(1,52)$ $=1.99, \mathrm{p}=0.164)$ or gender $(\mathrm{F}(1,52)=0.06, \mathrm{p}=0.811)$. Likewise, the MANOVA on decision time for the second response showed a main effect for navigational aid $(F(3,156)$ $=40.14, \mathrm{p}<0.001)$, but not for age $(\mathrm{F}(1,52)=3.06, \mathrm{p}=0.084)$ or gender $(\mathrm{F}(1,52)=$ $0.88, \mathrm{p}=0.352$ ). These results mean that both age groups improved their accuracy and decision times for the second response.

For the analyses described throughout the report, the responses were combined because the combined responses provided a measure that captures the subject's overall, total performance. 


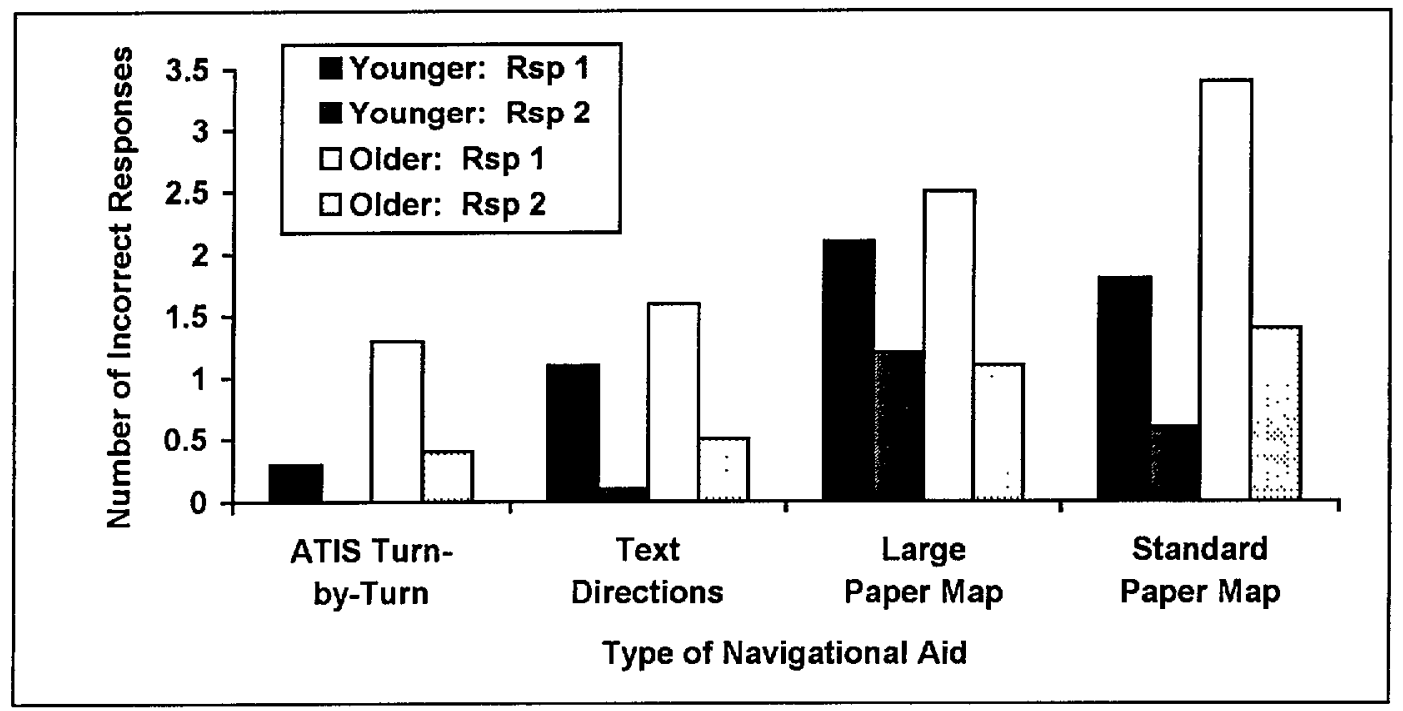

Rsp $=$ Response

Figure 12. Accuracy for responses 1 and 2 by age group and navigational aid.



Rsp $=$ Response

Figure 13. Decision time for responses 1 and 2 by age group and navigational aid. 


\section{APPENDIX E. RESULTS OF SIMULATIONS MULTIPLE REGRESSION ANALYSES PREDICTING ACCURACY OR DECISION TIME WITH THE COGNITIVE TEST SCORES}

Table 17. Accuracy with ATIS.

\begin{tabular}{||l|c|c|c||}
\hline \multicolumn{1}{|c|}{ Cognitive Test } & Standardized Beta & $\mathrm{R}^{2}$ & $\mathrm{~F}$ \\
\hline Perceptual Speed & $-0.377^{\prime \prime}$ & & \\
\hline Verbal Ability & -0.04 & & \\
\hline Spatial Ability & -0.27 & & \\
\hline \multicolumn{2}{|l|}{} \\
\hline
\end{tabular}

$* \mathrm{p}<0.01$

Table 18. Accuracy with text directions.

\begin{tabular}{|c|c|c|c|}
\hline Cognitive Test & Standardized Beta & $\overline{\mathrm{R}^{2}}$ & $\bar{F}$ \\
\hline Perceptual Speed & 0,02 & & \\
\hline Verbal Ability & $.0,08$ & & \\
\hline Spatial Ability & $.0,50 "$ & & \\
\hline & & 0.28 & $6.76^{\prime \prime}$ \\
\hline
\end{tabular}

$* \mathrm{p}<0.01$

Table 19. Accuracy with the large paper map.

\begin{tabular}{||l|c|c|c||}
\hline \hline \multicolumn{1}{|c|}{ Cognitive Test } & Standardized Beta & $\mathrm{R}^{2}$ & $\mathrm{~F}$ \\
\hline Perceptual Speed & 0.21 & & \\
\hline Verbal Ability & $\cdot 0,06$ & & \\
\hline Spatial Ability & $\cdot 0.50^{\prime \prime}$ & & \\
\hline \multicolumn{2}{|l|}{} & 0.18 & $3.90^{\prime \prime}$ \\
\hline
\end{tabular}

$* \mathrm{p}<0.01$

Table 20. Accuracy with the standard paper map.

\begin{tabular}{||l|c|c|c||}
\hline \hline \multicolumn{1}{|c|}{ Cognitive Test } & Standardized Beta & $\mathrm{R}^{2}$ & $\mathrm{~F}$ \\
\hline Perceptual Speed & -0.10 & & \\
\hline Verbal Ability & -0.03 & & \\
\hline Spatial Ability & $-0.39 "$ & & \\
\hline & & 0.23 & $5.07^{\prime \prime}$ \\
\hline
\end{tabular}

$* p<0.01$ 
Table 21. Decision time with ATIS.

\begin{tabular}{|c|c|c|c|}
\hline Cognitive Test & Standardized Beta & $\overline{\mathrm{R}^{2}}$ & $\bar{F}$ \\
\hline Perceptual Speed & $-0.42 ” " '$ & & \\
\hline Verbal Ability & -0.18 & & \\
\hline Spatial Ability & -0.08 & & \\
\hline & & 0.33 & $8.52 *$ \\
\hline
\end{tabular}

Table 22. Decision time with the text directions.

\begin{tabular}{||l|c|c|c||}
\hline \hline \multicolumn{1}{|c|}{ Cognitive Test } & Standardized Beta & $\mathrm{R}^{2}$ & $\mathrm{~F}$ \\
\hline Perceptual Speed & -0.23 & & \\
\hline Verbal Ability & $-0.34 ”$ & & \\
\hline Spatial Ability & -0.19 & & \\
\hline \multicolumn{2}{|l}{} & 0.39 & $11.19 ”$ \\
\hline
\end{tabular}

$* p<0.01$

Table 23. Decision time with the large paper map.

\begin{tabular}{||l|c|c|c||}
\hline \hline \multicolumn{1}{|c|}{ Cognitive Test } & Standardized Beta & $\mathrm{R}^{2}$ & $\mathrm{~F}$ \\
\hline Perceptual Speed & $-0.35 ”$ & & \\
\hline Verbal Ability & -0.14 & & \\
\hline Spatial Ability & -0.11 & & \\
\hline \multicolumn{2}{|l|}{} \\
\hline
\end{tabular}

$* \mathrm{p}<0.01$

$* * \mathrm{p}<0.05$

Table 24. Decision time with the standard paper map.

\begin{tabular}{|c|c|c|c|}
\hline Cognitive Test & Standardized Beta & $\mathrm{R}^{2}$ & $\bar{F}$ \\
\hline Perceptual Speed & $-0.33^{\prime \prime}$ & & \\
\hline Verbal Ability & -0.22 & & \\
\hline Spatial Ability & -0.15 & & \\
\hline & & 0.33 & $8.65^{\prime \prime \prime}$ \\
\hline
\end{tabular}




\section{APPENDIX F. PREDICTING ACCURACY AND DECISION TIME WITH THE COGNITIVE TEST SCORES AND FACTOR SCORES}

Table 25. Accuracy with text directions.

\begin{tabular}{|l|c|c|c|}
\hline \multicolumn{1}{|c|}{ Variables } & Beta & $\mathrm{R}^{2}$ & $\mathrm{R}^{2}$ Change \\
\hline Gender & 0.01 & & \\
Age Group & -0.09 & 0.05 & 0.05 \\
\hline Perceptual Speed & -0.03 & & \\
Spatial Scanning & $-0.53 ”$ & $0.28^{*}$ & $0.23^{\prime}$ \\
\hline Wayfinding & -0.15 & & \\
Preference for Maps & -0.11 & $0.32^{\prime}$ & 0.03 \\
\hline
\end{tabular}

$$
* \mathrm{p}<0.05
$$

Table 26. Accuracy with the standard paper map.

\begin{tabular}{|l|c|c|c|}
\hline \multicolumn{1}{|c|}{ Variables } & Beta & $\mathrm{R}^{2}$ & $\mathrm{R}^{2}$ Change \\
\hline Gender & 0.07 & & \\
Age Group & 0.16 & 0.11 & $0.11^{* *}$ \\
\hline Perceptual Speed & 0.01 & & \\
Spatial Scanning & $-0.32 * *$ & 0.23, & $0.12^{\prime}, '$ \\
\hline Way finding & -0.03 & & \\
Preference for Maps & $-0.37 ”$ & $0.35 "$ & $0.11^{\prime \prime}$, \\
\hline
\end{tabular}

$$
\begin{aligned}
& * \mathrm{p}<0.05 \\
& * * \mathrm{p}<0.01
\end{aligned}
$$

Table 27. Accuracy with ATIS.

\begin{tabular}{|l|c|c|c|}
\hline \multicolumn{1}{|c|}{ Variables } & Beta & $\mathrm{R}^{2}$ & $\mathrm{R}^{2}$ Change \\
\hline Gender & 0.19 & & \\
Age Group & 0.09 & $0.24^{*}$ & $0.24^{*}$ \\
\hline Perceptual Speed & -0.27 & $0.35^{*}$ & \\
Spatial Scanning & $-0.30^{* *}$ & $0.40^{*}$ & $0.16^{*}$ \\
\hline Wayfinding & 0.11 & & \\
Preference for Maps & -0.04 & $0.41^{*}$ & 0.01 \\
\hline
\end{tabular}

$$
\begin{aligned}
& * \mathrm{p}<0.05 \\
& * * \mathrm{p}<0.01
\end{aligned}
$$


Table 28. Accuracy with the large map.

\begin{tabular}{|l|c|c|c|}
\hline \multicolumn{1}{|c|}{ Variables } & Beta & $\mathrm{R}^{2}$ & $\mathrm{R}^{2}$ Change \\
\hline Gender & 0.15 & & \\
Age Group & -0.08 & 0.01 & 0.01 \\
\hline Perceptual Speed & 0.22 & & \\
Spatial Scanning & $-0.49^{*}$ & 0.21 & $0.20^{*}$ \\
\hline Wayfinding & -0.16 & & \\
Preference for Maps & $-0.54^{*}$ & $0.47^{*}$ & $0.26^{*}$ \\
\hline
\end{tabular}

$* \mathrm{p}<0.05$
$* * \mathrm{p}<0.01$ 


\section{REFERENCES}

1. Yang, T.A.; Shekhar, S.; Hamidzadeh, B.; and Hancock, P.A. (1991). Path planning and evaluation in IVHS databases. In Vehicle Navigation and Information Systems Conference Proceedings: Part 1.

2. Je ffery, D , J. (198 1). Ways and Means of Improving Primary Route Guidance. TRRL Laboratory Report 1016, Crowthorn, U.K.: Transport and Road Research Laboratory.

3. Outram, V.E., and Thompson, E., (1977). Driver route choice. Proceedings of the PTRC Summer Annual Meeting. University of Warwick, U.K.

4. King, G. G. (1986). Economic Assessment of Potential Solutions for Improving Motorist Route Following. Report No. FHWA/RD/86/029, Washington D.C.: Federal Highway Administration.

5. Barr, R.A., and Eberhard, J.W. (1991). Special issue preface. Human Factors, 33, 497-498.

6. Waller, P.F. (1991). The older driver. Human Factors, 33, 499-505.

7. Federal Highway Administration (1981). Highway Statistics, 1980. Washington, D. C. : U.S. Government Printing Office.

8. Federal Highway Administration (1990). Highway Statistics, 1989. Washington, D.C.: U.S. Government Printing Office.

9. McDowd, J.M., and Birren, J.E. (1990). Aging and attentional processes. In J.E. Birren and K. Warner Schaie, (Eds.), Handbook of the Psychology of Aging (2nd ed.). New York: Van Nostrand and Reinhold.

10. Albert, MS. (1988). Cognitive function. In M.S. Albert and M.B. Moss (Eds.), Geriatric Neuropsychology. New York: The Guilford Press.

11. Ogden, J.A. (1990). Spatial abilities and deficits in aging and age-related disorders. In F. Boller and J. Grafman (Eds.), Handbook of Neuropsychology, Vol. 4. New York: Elsevier .

12. Per-ret, E., and Birri, R. (1982). Aging, performance decrements, and differential cerebral involvement. In S. Corkin, K.L. Davis, J.H. Growden, E. Usdin, R.J. Wurtman (Eds.), Alzheimer's disease: A report of progress (Aging, Vol. 19). New York: Raven Press. 
13. Salthouse, T.A. (1987). Adult age differences in integrative spatial ability. Psychology and Aging, 2, 254-260.

14. Hoyer, W. J., and Plude, D.J. (1980). Attentional and perceptual processes in the study of cognitive aging. In L. W. Poon (Ed.), Aging in the 1980s. Washington, D. C. : American Psychological Association.

15. Kline, D.W., and Schieber, F. (1986). Vision and aging. In J.E. Birren and K. Warner Schaie, (Eds.), Handbook of the Psychology of Aging (2nd ed.). New York: Van Nostrand Reinhold.

16. Shinar, D., and Schieber, F. (1991). Visual requirements for safety and mobility of older drivers. Human Factors, 33, 507-519.

17. Yee, D. (1985). A survey of the traffic safety needs and problems of drivers ages 55 and over. In J.L. Malfetti (Ed.), Drivers 55+: Needs and Problems of Older Drivers: Survey Results and Recommendations. Falls Church, VA: AAA Foundation for Traffic Safety.

18. Brouwer, W.H.; Waterink, W.; Van Wolffelaar, P.C.; and Rothengatter, T. (1991). Divided attention in experienced young and older drivers: Lane tracking and visual analysis in a dynamic driving simulator. Human Factors, 33, 573-582.

19. Walsh, D.; Krauss, I.; and Regnier, R. (1981). Spatial ability, environmental knowledge, and environmental use: The elderly. In L. Libon, A. Patterson, and N. Newcombe (Eds.), Spatial Representation and Behavior Across the Life Span. New York: Academic Press.

20. Kirasic, K.C., and Allen, G.L. (1985). Aging, spatial performance and spatial competence. In N. Charness (Ed.), Aging and Performance. Chichester, England: John Wiley.

21. Ohta, R.J. (1983). Spatial orientation in the elderly: The current status of understanding. In H.L. Pick, Jr. and L.P. Acredolo (Eds.), Spatial Orientation: Theory, Research, and Application. New York: Plenum Press.

22. McDowd, J.M., and Craik, F.I.M. (1988). Effects of aging and task difficulty on divided-attention performance. Journal of Experimental Psychology: Human Perception and Performance, 14, 267-280.

23. Carpenter, P.A., and Just, M.A. (1986). Spatial ability: An information processing approach to psychometrics. In R.J. Sternberg (Ed.), Advances in the Psychology of Human Intelligence: Vol. 3. New Jersey: Lawrence Erlbaum Associates. 
24. Lohman, D . F. (1979). Spatial Ability: A Review and Reanalysis of the Correlational Literature. (Technical Report No. 8). Stanford, CA: Stanford University, Aptitude Research Project, School of Education. (NTIS NO. AD-A075 972).

25. Lohman, D.F. (1988). Spatial abilities as traits, processes, and knowledge. In R.J. Sternberg (Ed.), Advances in the Psychology of Human Intelligence: Vol. 3. New Jersey: Lawrence Erlbaum Associates.

26. Pellegrino, J.W., Alderton, D.L., and Shute, V.J. (1984). Understanding spatial ability. Educational Psychologist, 3, 239-253.

27. McGee, M.G. (1979). Human spatial abilities: Psychometric studies and environmental, genetic, hormonal, and neurological influences. Psychological Bulletin, 86, 889-918.

28. McGee, M.G. (1982). Spatial abilities: The influence of genetic factors. In M. Potegal (Ed.), Spatial Abilities: Development and Physiological Foundations. New York: Academic Press.

29. Poltrock, S.R., and Agnoli, F. (1986). Are spatial visualization ability and visual imagery ability equivalent? In R.J. Sternberg (Ed.), Advances in the Psychology of Human Intelligence: Vol. 3. Hillsdale, NJ: Lawrence Erlbaum Associates.

30. Goldin, S.E., and Thorndyke, P.W. (1981). An Analysis of Cognitive Mapping Skill. Santa Monica, CA: The Rand Corporation, Technical Report No. N-1664-ARMY.

3 1. Thorndyke, P. W., and Goldin, S .E. (1983). Spatial learning and reasoning skill. In H.L. Pick, Jr. and L.P. Acredolo, (Eds.), Spatial Orientation: Theory, Research and Application. New York: Plenum Press.

32. Thorndyke, P. W., and Stasz, C. (1980). Individual differences in procedures for knowledge acquisition from maps. Cognitive Psychology, 12, 137-175.

33. Streeter, L.A., and Vitello, D. (1986). A profile of drivers' map-reading abilities. Human Factors, 28, 223-239.

34. Kozlowski, L., and Bryant, K. (1977). Sense of direction, spatial orientation, and cognitive maps. Journal of Experimental Psychology: General, 3, 590-598.

35. McKnight, A.J., and McKnight, A.S. (1992). The Effect of In-Vehicle Navigation Information Systems Upon Driver Attention. Landover, MD: National Public Services Research Institute. 
36. Walker, J.; Sedney, C.A.; and Mast, T. (1991). Older Drivers and Useful Field of View in a Part-Task Simulator. (Paper No. 920702). Washington, D.C. : Transportation Research Board.

37. Ekstrom, R.B.; French, J.W.; and Harmen, H.H. (1976). Manual for Kit of FactorReferenced Cognitive Tests. Princeton, NJ: Educational Testing Service.

38. Steiger, J.H. (1980). Tests for comparing elements of a correlation matrix. Psychological Bulletin 87, 245-251.

39. Shinar, D. (1978). Psychology on the Road: The Human Factor in Traffic Safety. New York: John Wiley \& Sons. 